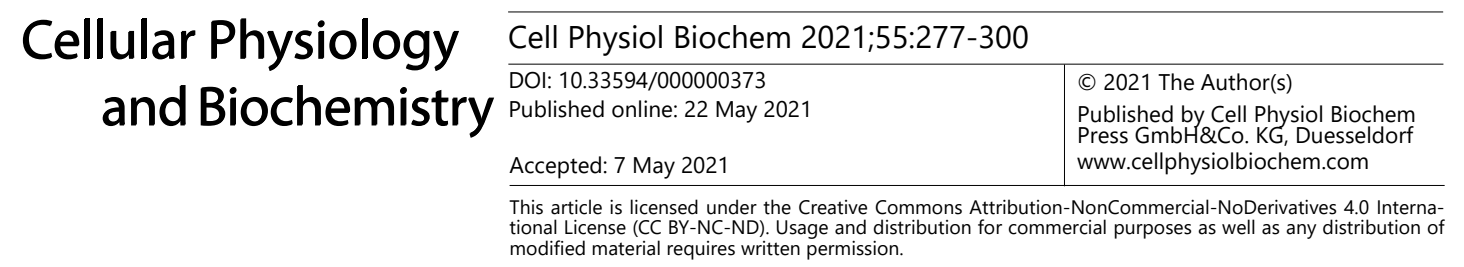

Review

\title{
Lysosome Function in Cardiovascular Diseases
}

\author{
Owais M. Bhat Pin-Lan Li \\ Department of Pharmacology and Toxicology, Virginia Commonwealth University, School of Medicine, \\ Richmond, VA, USA
}

\section{Key Words}

Lysosome • Smooth Muscle Cells • Exosomes $・$ Sphingolipids • Vascular Calcification

\begin{abstract}
The lysosome is a single ubiquitous membrane-enclosed intracellular organelle with an acidic $\mathrm{pH}$ present in all eukaryotic cells, which contains large numbers of hydrolytic enzymes with their maximal enzymatic activity at a low $\mathrm{pH}(\mathrm{pH} \leq 5)$ such as proteases, nucleases, and phosphatases that are able to degrade extracellular and intracellular components. It is well known that lysosomes act as a center for degradation and recycling of large numbers of macromolecules delivered by endocytosis, phagocytosis, and autophagy. Lysosomes are recognized as key organelles for cellular clearance and are involved in many cellular processes and maintain cellular homeostasis. Recently, it has been shown that lysosome function and its related pathways are of particular importance in vascular regulation and related diseases. In this review, we highlighted studies that have improved our understanding of the connection between lysosome function and vascular physiological and pathophysiological activities in arterial smooth muscle cells (SMCs) and endothelial cells (ECs). Sphingolipids-metabolizingenzymes in lysosomes play critical roles in intracellular signaling events that influence cellular behavior and function in SMCs and ECs. The focus of this review will be to define the mechanism by which the lysosome contributes to cardiovascular regulation and diseases. It is believed that exploring the role of lysosomal function and its sphingolipid metabolism in the initiation and progression of vascular disease and regulation may provide novel insights into the understanding of vascular pathobiology and helps develop more effective therapeutic strategies for vascular diseases.

(c) 2021 The Author(s). Published by Cell Physiol Biochem Press GmbH\&Co. KG
\end{abstract}

\section{Introduction}

Christian de Duve, in 1974 received the Nobel Prize for his work on lysosome structure and functions. Lysosomes are acidic, spherical, membrane-bound organelles within a cell. They contain various hydrolytic enzymes that catalyze hydrolysis reactions. The synthesis of lysosome proteins is similar to other proteins. Hydrolytic enzymes synthesized in rough 
endoplasmic reticulum and tagged with mannose-6-phosphate within the Golgi apparatus are targeted to the lysosome. Vesicles containing these hydrolytic enzymes bud off from the Golgi apparatus and in the cytoplasm, these vesicles bind with late endosomes. The late endosomes can eventually mature into lysosomes. $\mathrm{H}^{+}$-ATPase residing on lysosomal membrane leads to acidification of lysosomes, which facilitates the activity of various acid hydrolases. Entry of calcium $\left(\mathrm{Ca}^{2+}\right)$ into lysosomal compartment is carried out by $\mathrm{H}^{+} / \mathrm{Ca}^{2+}$ exchange under resting condition and released under various stimulations $[1,2]$.

The hydrolytic enzymes within the lysosome allow them to destroy foreign particles via a cellular process known as phagocytosis. Lysosomes provide a defense system to the cell against entry of various pathogens via endocytic process before these pathogens are delivered to the cytoplasm [3]. The enzymes within the lysosomes work in an oxygenindependent mechanism in killing various pathogens. In addition, the lysosomes are involved in breakdown of many biomolecules, misfolded proteins and damaged organelles as part of the recycling system of the cell [4]. Moreover, lysosomes also play an important role in oocyte maturation and fertilization during acrosome reaction, the sperm head contains lysosomal enzymes which effectively bore a hole through the egg membrane, thereby facilitating the entry of sperm into the egg [5].

In addition to its crucial role in phagocytosis, the lysosome has been well known to participate in autophagy, a catabolic process to degrade cytoplasmic components and organelles that maintain cellular homeostasis. The term "Autophagy" term was coined in the 1960s and was classified into three categories, which include microautophagy, macroautophagy and chaperone-mediated autophagy. Macroautophagy is a major regulator of catabolic mechanisms and has been well characterized in eukaryotic cells, this process is used to degrade damaged or long-lived proteins and organelles [6, 7]. Although the autophagy term was coined in 1960s, knowledge regarding its morphological and biochemical characteristics was unveiled in the early 1990s. In the past decade, owing to the discovery of yeast autophagy genes (Atg genes) followed by their identification with the mammalian homologues, several studies elucidated the molecular machinery of this main cellular homeostatic process and its regulatory mechanisms $[8,9]$. The autophagic process involves 4 stages including induction, autophagosome (AP) formation, docking and fusion with lysosomes (namely, the formation of autophagolysosome (APLs) or autolysosomes), and breakdown of autophagic vesicles [10]. Our laboratory also focused on such mechanisms revealing that the normal regulation of lysosome trafficking and fusion is controlled by nicotinic acid adenine dinucleotide phosphate (NAADP) or ceramide as well as lysosomal and cytosolic $\mathrm{Ca}^{2+}$ levels [11].

Lysosomal storage disorders (LSDs) are major category of lysosome dysfunction that contributes to cardiovascular disorders. Deficiency of lysosomal enzymes, membrane transporters, or several other proteins that are involved in lysosomal biology are main causes of LSDs [12]. Many patients suffering from LSDs show severe cardiac phenotypes including coronary artery disorders. Mutational disorders in lysosomal genes have been identified as causative factors, which are responsible for the disease pathogenesis. For example, Fabry disease is caused by a deficiency in the lysosomal enzyme alpha-galactosidase A $(\alpha-G a l$ A), an enzyme involved in sphingolipid metabolism, leading to buildup of the fatty acid globotriaosylceramide (Gb3) in the walls of the blood vessels and other organs of the body [13]. Besides LSDs, lysosome dysfunction has been recently reported to play an important role in the development of different human diseases [14, 15]. This review will briefly summarize current evidences that lysosome regulation and dysfunction may be implicated in the pathogenesis or pathophysiology of cardiovascular diseases such as vascular calcification, arterial stiffening, and atherosclerosis. 


\section{Lysosome and Cardiovascular Diseases}

With respect to cardiovascular regulation and disease, many studies have demonstrated that abnormal autophagy including autophagic flux has a variety of pathogenic actions on the cardiovascular system. For example, Transcription Factor EB (TFEB) is a transcription factor, master regulator of autophagy and lysosome biogenesis genes. Macrophage-specific overexpression of TFEB in a mice model lead to atheroprotection. It was observed that overexpression of TFEB is associated with atheroprotection including reductions in plaque burden including apoptotic and necrotic areas [16]. Mechanistically, TFEB decreases accumulation of ubiquitinated and SQSTM1-enriched protein aggregates, IL1B/IL-1 $\beta$ levels, and macrophage apoptosis. TFEB stimulates endocytosis, phagocytosis that help macrophages to engulf apoptotic cells in atherosclerosis. In addition, TFEB drives the expression of lipid metabolic and mitochondrial genes via transcriptional activation of PPARGC1A/PGC-1 $\alpha$. Deficiency of lysosomal-associated membrane protein-2 (Lamp-2) gene, which encodes for a lysosomal membrane protein on chromosome $\mathrm{X}$ causes Danon disease, which often leads to cardiomyopathy/ heart failure. In human cardiomyocytes, autophagosome-lysosome fusion requires Lamp-2 isoform B (Lamp-2B). In addition, gene correction of Lamp-2 mutation rescues the Danon phenotype [17]. This study provided an evidence for cardiomyopathy in Danon patients and suggested defective Lamp-2B-mediated autophagy as a therapeutic target to treat this patient population.

Lysosome has been known to regulate endothelial function, and it participates in transmembrane signaling of different death receptors via formation of membrane rafts (MRs) redox signaling platforms, thereby leading to endothelial dysfunction upon different stimuli [18]. During atherosclerosis, lysosome-associated membrane signalosome plays a crucial role in endothelial injury such as abnormal leukocyte adhesion, invasion or infiltration of macrophages, and local oxidative stress. During atherosclerosis, macrophages uptake the oxidized form of cholesterol through scavenger receptors and deliver to lysosomes through endocytic process for degradation. Under normal condition, lysosomal acid lipase hydrolyzed the cholesteryl esters into free cholesterol, which is then transported in an ATP dependent process out of lysosomes through lysosomal Niemann-Pick type C1 protein. This catabolism and transport of cholesterol in lysosomes are regulated by a number of lysosomal molecules such as acid sphingomyelinase (ASMase), mucolipin-1, and $\mathrm{H}^{+}$-ATPase. Any defect in these events may cause accumulation of cholesterol into the lysosomes and deficient clearance of cholesterol from macrophages. These events lead to lipid deposition, foam cell formation and ultimately to atherosclerosis. Cardiovascular disease is the leading cause of death worldwide. According to the American Heart Association 2018 report [19], cardiovascular disease accounts for more than 800,000 , or approximately one in three, deaths in the United States each year. Although, there are various underlying causes or causative factors which contribute to the pathogenesis of cardiovascular diseases, lysosome function is strongly correlated with the development and progression of these diseases [15]. More detailed information about the critical role of lysosomes in several major vascular diseases is discussed below.

\section{Vascular Calcification}

Vascular calcification is a pathology characterized by deposition of dispersed punctate or hydroxyapatite patchy crystals. It is characteristic of aging and also contributes to diabetes mellitus, atherosclerosis and chronic kidney disease (CKD) [20]. Vascular calcification localized to atherosclerotic neointima is known as intimal calcification and is detected as microcalcification (range: $\geq 0.5$ to $<15 \mu \mathrm{m}$ ). It is assumed that microcalcification is originated from apoptotic smooth muscle cells (SMC) or matrix vesicles that are released by these SMCs. It occurs near the internal elastic lamina and is associated with lipid deposition and inflammation in the neointima [21]. Vascular calcification histologically located in medial layer of the vessel, known as arterial medial calcification (AMC), surrounding the arterial medial SMCs and along the elastic lamellae is also known as Monckeberg's medial sclerosis. 
It reduces the arterial compliance and is prevalent in diabetes mellitus and CKD. The pathogenesis of AMC is still poorly understood however; the process is believed to mimic the skeletal bone formation [22]. AMC is a complex and highly regulated process which involves the reprogramming and osteochondrogenic differentiation of vascular smooth muscle cells (VSMCs) and secretion of calcifying matrix vesicles or apoptotic bodies generated from these VSMCs which initiates deposition of calcium/phosphate $\left(\mathrm{Ca}^{2+} / \mathrm{P}_{\mathrm{i}}\right)$ crystals in the arterial wall [23-25].

From the last decade, studies are citing the role of sphingolipids in vascular calcification. A study in VSMCs showed that sphingosine-1-phosphate (S1P) stimulates the phosphorylation of ezrin-radixinmoesin (ERM) axis increasing mineralization; however, inhibition of ASMase and ceramidase prevented S1P level increase, ERM activation, and mineralization [26]. S1P is also involved in trans-differentiation and calcification of valve interstitial cells that contributes to valve calcification [27]. Song et al. [28] showed that

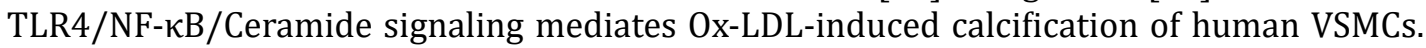
In patients with cystic echinococcosis (CE), relative expression of Asah1 gene (codes for acid ceramidase) was low in patients with calcification [29]. In human femoral arterial SMCs, Ox-LDL-induced matrix mineralization was mediated via ceramide, which was attributed to increased neutral-sphingomyelinase (N-SMase) activity and ceramide levels [30]. Kapustin et al. also reported that N-SMase2 inhibition reduces mineralization in response to osteogenic medium in human coronary artery SMCs [25]. In sphingolipid catabolism, markedly increased levels of Sphingosine-1-Phosphate Lyase 1 (SGPL1) substrates, S1P and sphingosine was observed in the patient's blood and fibroblasts, accompanied with adrenal calcifications and vascular alterations in renal biopsies, which were consistent with changes seen in Sgpl1 knockout mice [31]. A study in patients with coronary calcification identified 103 lipids including the sphingolipid and sterol lipid classes might aid in better assessment of patients with subclinical coronary artery disease [32].

Recently, our group explored the role of lysosomal-sphingolipid metabolism in the vascular calcification and these findings provide the first experimental evidence in this area. Our findings revealed that SMC specific deletion of acid ceramidase (Ac) or overexpression of ASMase leads to the accumulation of ceramide in the arterial SMCs which plays a key role in osteogenic phenotype transition, increased small extracellular vesicle (sEV) secretion and mineral deposition in these cells that contribute to AMC. In addition, we found that GW4869, a N-SMase inhibitor significantly decreased $\mathrm{P}_{\mathrm{i}}$-induced calcification in coronary arterial smooth muscle cells (CASMCs) [33]. Moreover, ASMase inhibition by amitriptyline, a pharmacological inhibitor of ASMase significantly reduced CASMCs calcification both in vitro and in vivo [34]. These findings provide a novel insight into the molecular mechanisms associated with the sphingolipid-ceramide pathway required for osteogenic lineage reprogramming of SMCs that result in AMC, and indicate new therapeutic strategies for the prevention and treatment of vascular calcification. Three major molecular mechanisms as discussed below are proposed to address the contribution of lysosomes and related enzymes to the vascular calcification.

Phenotypic change of VSMCs. VSMCs can undergo phenotypic switching from contractile (differentiated) phenotype to synthetic (dedifferentiated) phenotype in response to various stimuli including growth factors, cell adhesion molecules, chemotactic factors, extracellular matrix (ECM) enzymes, and injury stimuli signals [35, 36]. This phenotypic transition of VSMCs is associated with their proliferation and is one of the major contributing factors for the initiation of vascular remodeling in hypertension, atherosclerosis and vascular restenosis $[37,38]$. Synthetic or dedifferentiated VSMCs showed increased viability in proliferation, migration, and synthesis, and reduced expression of differentiation markers $\alpha$-SMA and SM22- $\alpha[39,40]$.

VSMCs have been shown to undergo differentiation to osteoblast-like cells. Bonerelated transcription factors, including MSX2, RUNX2, SOX9, and osterix, which promote osteogenesis have been found in SMCs in calcified blood vessels. Osteo inductive cytokines such as tumor necrosis factor- $\alpha$ (TNF- $\alpha$ ) upregulate expression of the transcription factors 
RUNX2 and osterix via activation of MSX2 and Wnt signaling pathway [22, 41]. In high-fat diet fed low-density lipoprotein (LDL) receptor knockout mouse model, increased serum TNF- $\alpha$ levels were found to be associated with augmented aortic expression of bone morphogenetic protein-2 (BMP-2), MSX2, Wnt3a, Wnt7a and aortic calcification [42]. RUNX2, a protein related to osteoblast differentiation in turn upregulates various bone-related proteins such as osteocalcin, sclerostin, and receptor activator of nuclear factor-kappa $\beta$ ligand (RANKL) [43]. Osterix activated a repertoire of genes during differentiation of preosteoblasts into mature osteoblasts and osteocytes including bone sialoprotein and alkaline phosphatase (ALP) $[22,44,45]$.

Under normal physiological conditions, spontaneous accumulation of $\mathrm{Ca}^{2+} / \mathrm{P}_{\mathrm{i}}$ levels are tightly balanced in the vasculature [46]. However, imbalanced mineral metabolism led to increased intracellular phosphate levels in VSMCs which directly drive their osteogenic differentiation and mineralization, inducing expression of osteogenic markers as shown in Fig. $1[47,48]$. Under in vitro conditions, VSMCs exposed to a calcifying environment lost SMC lineage markers such as SM22 $\alpha$ and SM $\alpha$-actin and increased expression of the osteogenic markers such as RUNX2, osteocalcin, osteopontin, and ALP was observed [47]. In addition, increased expression of RUNX2 independent of downregulation of myocardin and SMC contractile proteins was found to be important for osteogenic switch and calcification [49]. Ex vivo human samples and animal models of arterial calcification demonstrated that free serum $\mathrm{Ca}^{2+} / \mathrm{P}_{\mathrm{i}}$ levels caused ossification of soft tissue [50-52]. Increased serum $\mathrm{Ca}^{2+} / \mathrm{P}_{\mathrm{i}}$ levels are correlated with the development and progression of calcification in human subjects [53]. Mineral imbalance actively stimulates phenotypic transformation of VSMCs during calcification process. In vitamin D (Vit D)-induced calcification mouse model, increased RUNX2 expression was observed [54], akin to CKD patient's high doses of Vit D is correlated with severity of calcification [55]. Several in vivo studies demonstrated that physiologically Vit D promotes AMC through abnormal mineral metabolism $\left(\mathrm{Ca}^{2+} / \mathrm{P}_{\mathrm{i}}\right)$, which as reported lead to vascular osteogenesis and mineralization $[56,57]$. Our study in $S m p d 1^{\text {trg }} / \mathrm{SM}^{\text {cre }}$ mice with SMC-specific overexpression of Smpd1 gene showed that lysosomal acid sphingomyelinase (murine gene code: Smpd1)-derived ceramide contributes to the phenotypic switch in SMCs which leads to AMC. A high dose of Vit D $(500000 \mathrm{IU} / \mathrm{kg} / \mathrm{d})$ resulted in increased AMC associated with augmented expression of RUNX2 and osteopontin in the coronary and aortic

Fig. 1. Phenotype switch of VSMCs and exosome secretion. Upon various stimuli VSMCs may be subjected to oxidative stress, ER stress, increased calcium $\left(\mathrm{Ca}^{2+}\right)$ and phosphate $\left(\mathrm{P}_{\mathrm{i}}\right)$ levels, upregulation of osteogenic markers and phenotype change. Under such conditions SMCs may produce and release large number of exosomes (30-100 nm) which are composed of lipid bilayer membrane and usually carries lipids, DNA, RNA (Non-coding RNAs such as mRNA, miRNA, LncRNA, and circRNA) and proteins including annexins, alkaline phosphatase, oxidant stress proteins and surface membrane proteins etc. VSMCs: Vascular smooth muscle cells; ER: Endoplasmic Reticulum.
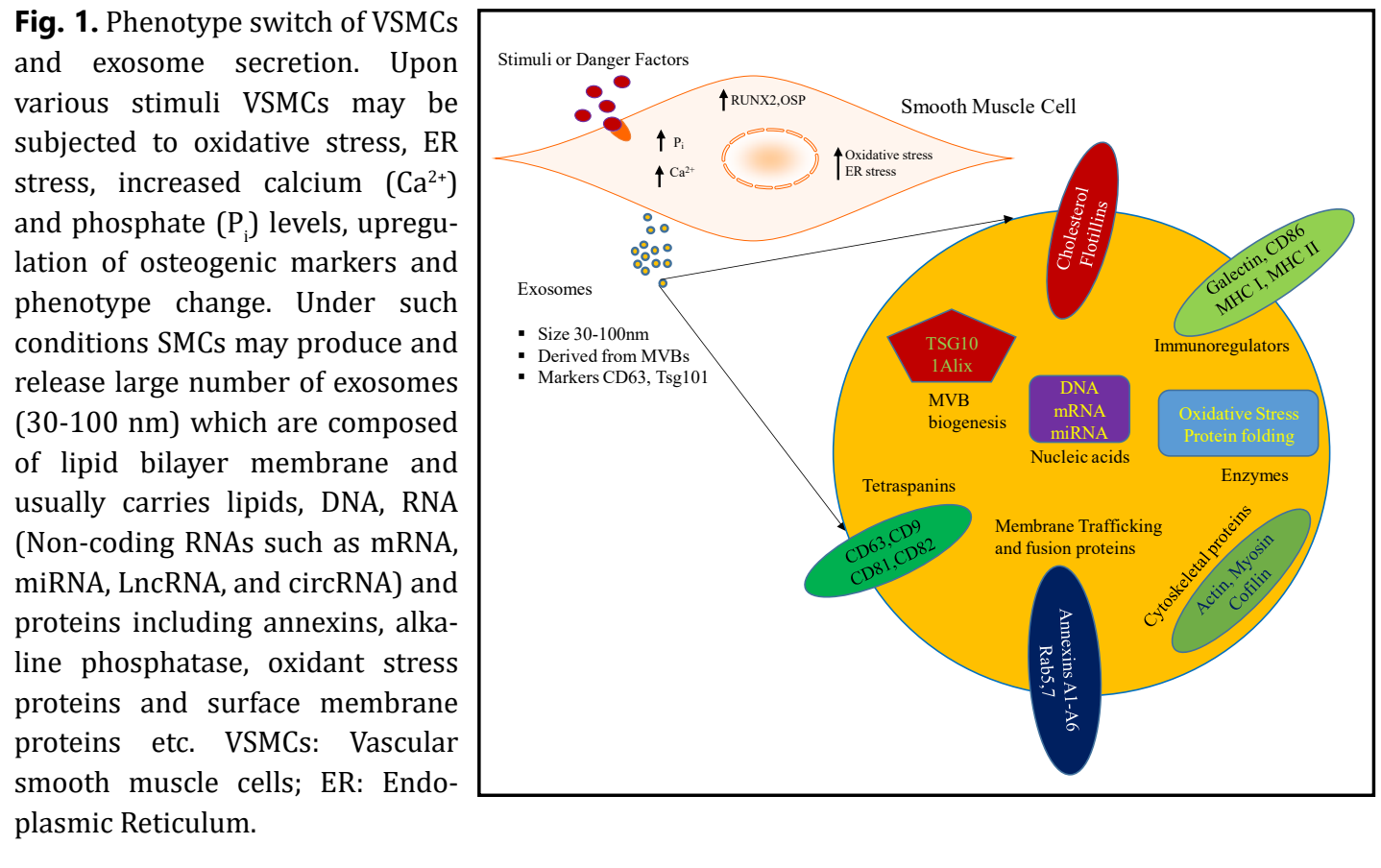
media, indicating phenotypic switch. However, amitriptyline, an ASMase inhibitor, reduced calcification and reversed phenotypic switch. These data indicate that lysosomal ceramide plays a critical role in phenotype change in SMCs, which may contribute to the arterial stiffness during the development of AMC [34]. Furthermore, our group reported that Asah1 gene (which encodes for acid ceramidase (Ac)) deletion specifically in SMCs in Asah $1^{\mathrm{fl} / \mathrm{fl}} / \mathrm{SM}^{\text {cre }}$ mice displayed more severe AMC in both coronary arteries and aorta receiving a high dose of Vit D which contributed to phenotypic change in arterial medial SMCs. Marked increase in osteopontin and RUNX2 (osteogenic markers) was observed in the arterial media of these mice [33]. These findings were validated in vitro using cultured CASMCs from $A s a h 1^{\mathrm{fl} / \mathrm{fl}} / \mathrm{SM}^{\mathrm{cre}}$ mice treated with high $\mathrm{P}_{\mathrm{i}}$. In this study, we also found that Lysosomal transient receptor potential mucolipin 1 (TRPML1) channels regulating lysosome interaction with multivesicular bodies (MVBs) contributes to this phenotypic switch in these cells. Furthermore, in another study, we employed Vit D-induced mucolipin knockout mice model to explore the role of TRPML1 channel in the AMC. We found that lysosomal expression of mucolipin-1, a product of the mouse Mcoln1 gene, which regulates lysosomal positioning contributes to the phenotypic transition of arterial SMCs [58].

Exosome release and calcifying nidus formation. Vascular calcification is tightly controlled by a series of endogenous factors. A study under in vivo and in vitro conditions showed effects of lysosomal and endosomal inhibition on vascular calcification. The study revealed that the lysosomal inhibitor chloroquine and the endosomal inhibitor dynasore enhanced $\mathrm{Ca}^{2+} / \mathrm{P}_{\mathrm{i}}$-mediated VSMC calcification and promoted osteogenic transformation of VSMCs [59]. Moreover, ex-vivo, $\mathrm{P}_{\mathrm{i}}$-induced medial calcification of aortic rings was increased by lysosome inhibition, indicating that the endosome-lysosome system may play a protective role in VSMC and AMC.

Extracellular vesicles (EVs) are membrane-enclosed particles secreted by cells such as matrix vesicles, microparticles, exosomes, ectosomes, microvesicles, MVBs and apoptotic bodies which are widely distributed in biological fluids [60]. They are composed of a lipid bilayer membrane and usually carry lipids, soluble proteins and RNA (Non-coding RNAs such as mRNA, miRNA, LncRNA, and circRNA) as shown in Fig. 1. Recently, EVs are hotspot for academic research especially exosomes, microvesicles (formerly known as microparticles) and apoptotic bodies [61]. The endosomal network carries out exosome formation, endosomes are divided into early, late, and recycled endosomes. These late endosomes containing internal vesicles formed following the inward budding of the outer endosomal membrane are called MVBs which will fuse with lysosomes and undergoes degradation [62]. In addition, fusion of late endosomes with plasma membrane release 30-100 $\mathrm{nm}$ vesicles to the outer space of cells that are known as exosomes [63] as shown in Fig. 1.

Exosomes also known as small EVs (sEVs) are released from stem cells, cardiomyocytes, ECs, SMCs platelets and adipose cells and contain potential valuable biological information, which contributes to the development and progression of coronary artery disease [64]. Cells secrete EVs in various microenvironments and into body fluids, playing a crucial role in cell to cell communication in neighboring regions (paracrine manner) or distant cell's (endocrine) via miRNAs and other mediators in various diseases including in cardiovascular diseases $[65,66]$. Under pathological conditions, EVs originating from VSMCs, stromal cells and macrophages play a crucial role in vascular calcification [67]. EVs are involved in various pathophysiological processes such as inflammation, proliferation, thrombosis and vasoactive reactions, and form microcalcifications in areas with sparse collagen within the cap of extracellular matrix leading to atherosclerotic plaque instability $[64,68]$. These vesicles serve as intercellular communication messengers thus influencing vascular repair and remodeling by VSMC phenotypic modulation during atherosclerotic process [69].

Studies in the ECs and macrophages have shown that TNF- $\alpha$ and BMP-2 through the formation of endothelial microparticles (EMPs) contribute to the osteogenic differentiation and calcification of VSMCs [70, 71]. Moreover, decreased Matrix Gla protein (MGP) and Glarich protein (GRP) levels may enhance VSMCs osteogenic differentiation and the release of 
calcifying competent EVs lacking MGP and GRP inhibitors mediated by BMP-2 osteogenic signaling. Enhanced microcalcification in chronic renal disease points towards the contribution of macrophages which release calcifying EVs enriched in S100A9 and annexin $\mathrm{V}$ that may directly impact vascular calcification and mineralization [72]. Microvesicles in the plasma of the elderly subjects and CKD patients enriched with $\mathrm{Ca}^{2+}$ and BMP2 promote osteogenic transformation of VSMCs. Also, microvesicles released from aging ECs promote calcification of VSMCs [73]. The cross talk between ECs and VSMCs via EVs is an important part of vascular remodeling which affect vascular function.

Recently, our laboratory reported that increased sEV secretion from SMCs is associated with AMC. In the Vit D-induced calcification mice model, we observed increased aortic and coronary AMC, associated with increased CD63, AnX2 (exosome markers) and ALP levels in the arterial wall, accompanied by reduced co-localization of lysosome marker (Lamp-1) with MVB marker (VPS16), a parameter for lysosome-MVB interaction [33, 34]. Increased arterial stiffness and elastin disorganization were also observed in these mice models. Under in vitro conditions, we found increased SEV secretion and decreased lysosome-MVB interaction in $\mathrm{P}_{\mathrm{i}}$-induced CASMC calcification model. Furthermore, our findings revealed that TRPML1 channels regulating lysosome (Lamp-1, lysosome marker) interaction with MVBs (VPS16, MVB marker) contributes to AMC [33, 34]. In another study in Mucolipin KO mice (Mcoln 1\%) mice, we extrapolated these in vitro findings of role of TRPML1 channel in regulating lysosome interaction with MVBs and sEV secretion during AMC as shown in Fig. 2. Besides validating the findings regarding AMC and sEV secretion as in our pervious animal models, furthermore we found that Mcoln $1 \%$ decreased co-localization of lysosome marker (Lamp1) with lysosome coupling marker (Rab 7 and ALG-2) in the aortic wall of Mcoln $1^{-/}$mice as compared to their wild-type littermates [58] indicating abnormal lysosome positioning and increased sEV secretion, which may contribute to the arterial stiffness characteristic of AMC. These findings add to the complex mechanistic pathways involved in the development and progression of AMC, which may be targeted for novel therapeutic potential for ameliorating this detrimental disease.

Fig. 2. Cross talk between ECs and SMCs during atherosclerosis. Various danger factors act on ECs which may induce lysosomal trafficking and fusion to cell membrane resulting in ceramide production via activation of ASMase leading to the formation of MR-Nox redox signalosomes. Nox-derived $0^{2--}$ lead to redox regulation of vascular endothelial and smooth muscle function which may lead to endothelial injury promoting atherosclerosis. SMCs switch from the 'contractile' to the 'synthetic' phenotype and migrate from the vessel's media into the intima. Atherosclerotic plaques are characterized by an accumulation of lipids, cholesterol loaded macrophage-derived foam cells, chemokines and cytokines. SMCs: Smooth muscle cells; CER: Ceramide; Nox: NADPH oxidase; SM: Sphingomyelin; ASMase: Acid Sphingomyelinase; LR: Lipid Rafts.




Abnormal extracellular matrix (ECM) metabolism. Under pathological situation, cross talk/intercellular communication through EVs can cause release of cytokines, excessive collagen, and matrix metalloproteinases (MMPs) by a large number of myofibroblasts. Thus, leading to valve fibrosis and remodeling thereby promoting the formation and production of osteoblast-like cells which ultimately lead to vascular calcification [74]. Matrix vesicles (MVs) contain endogenous calcification inhibitors MGP and circulating fetuin-A. During inflammation or mineral imbalance, VSMCs can undergo phenotypic switch to synthetic and promote the release of MVs, which leads to a calcified state of VSMC [25]. Physiologically, during vascular remodeling exosomes/sEVs derived from VSMC may drive cell adhesion, migration, and proliferation [25, 75]. During mineral imbalance, increased extracellular $\mathrm{Ca}^{2+} / \mathrm{P}_{\mathrm{i}}$ led to activation of sphingomyelin phosphodiesterase 3 , which resulted in increased VSMC exosome secretion and induced vascular calcification; however, inhibition of sphingomyelin phosphodiesterase 3 diminished exosome secretion and vascular calcification $[25,76]$. During the calcification process, there is externalization of phosphatidylserine, accumulation of annexin A6, metalloproteinase-2, and decrease of calcifying inhibitors, such as fetuin A, matrix Gla protein [77-79]. In human calcified carotid and femoral arteries, increased sortilin facilitates trafficking of tissue nonspecific alkaline phosphatase (TNAP) which leads to calcification [80]. In C2C12 myoblasts and chondrocytes, BMP-2induced RUNX2 expression stimulates sphingomyelin phosphodiesterase 3 suggesting a cross talk between exosome generation and osteogenic genes [81, 82]. As reported that vascular calcification is initiated by exosomes which are loaded with Gla [carboxyglutamic acid]-containing coagulation factors: IX and X, prothrombin, and proteins $\mathrm{C}$ and $\mathrm{S}$ [78, 83]. Prothrombin is a novel circulating vascular calcification inhibitor which activates coagulation pathways via Gla/ phosphatidylserine binding to exosomes. Hence, gradual loading of exosomes with prothrombin and prothrombin activation products diminishes both procalcification and procoagulant activities by Gla/ phosphatidylserine interactions, which will lead to vascular ECM remodeling and arterial wall degeneration [84].

In addition, endolysosomal system plays an important role in protein degradation, which are sorted into MVBs, and these MVBs fuse with the lysosomes leading to degradation of their contents. Lysosome plays a multifaceted role by controlling various cellular processes [4]. Late endosomal/lysosomal compartment contributes to recycling of active $\alpha 5 \beta 1$ integrin, which link to ECM internalization [85]. During endocytosis, $\alpha 5 \beta 1$ and its ligand fibronectin (FN) are delivered to late endosomes/lysosomes and proteolytic degradation of the FNcontaining ECM facilitated FN endocytosis or internalization [86]. Lysosomal-ECM network are also involved in lysosomal related disorders such as in mucopolysaccharidosis type I (MPS I), lysosomal alterations in MPS I promote leakage of cathepsin B which lead to increased total elastase activity in the aorta, however inhibition of cathepsin B improved elastin breaks [87]. Moreover, collagen I protein degradation via lysosome-dependent pathway contributes to the phenotypic switch of VSMCs [88]. Lysosomal enzyme, neuraminidase 1 influences the behavior of ECM molecules by altering the sialic acid content of various substrates, and deficiency of this enzyme causes sialidosis [89]. Another lysosomal enzyme arylsulfatase A stimulates adhesion of human microvascular endothelial cells in vitro, affecting architecture of the cytoskeleton and the distribution pattern of the cell adhesion-associated proteins thereby modulating cytoskeletal rearrangement, and its deficiency led to the manifestation of metachromatic leukodystrophy [90].

EVs contain surface polysaccharides and oligosaccharides which assemble a glycocalyx that regulates the interactions of EV with the target cells and the ECM through plasma membrane receptors, adhesion proteins and other molecules [91-93]. EVs carry proteoglycans such as Hyaluronan (HA), chondroitin sulfate and heparan sulfate which play a crucial role in their interactions with the ECM and bone mineralization $[94,95]$ and are involved in EVs function, uptake and secretion [96, 97]. In addition, MV-associated ECM glycoprotein tenascin $\mathrm{C}$ regulates bone mineralization activity [86]. EVs derived from hypoxic endothelial cells carry active lysyl oxidase-like 2 enzyme on their surface which facilitates collagen crosslinking in the ECM [87]. Presence of surface adhesion molecules and ligands 
on EV enable their interaction with ECM components such as laminin [88] or fibronectin [89] via integrins, and with HA via cluster of differentiation 44 (CD44) [88]. MMPs present in EVs degrade the basement membranes and other ECM components such as aggrecanase, which act on aggrecan-rich ECM that are components of connective tissues, typical of brain and cartilage [90]. EV interaction with the collage matrix act as a foci for the formation of small hydroxyapatite crystals, leading to the calcification of the ECM in vasculature. Additionally, annexins, calcium-binding proteins carried by EVs contribute to the formation of a nucleation complex on the EVs membrane, thereby initiating the mineralization of the ECM in blood vessels $[9,98,99]$. Kirsch and Pfäffle [100] found that anchorin CII (annexin V), a component of MV, binds specifically to Type II and Type X collagen and mediates binding of MV to the ECM, confirming that release of MV cargo occurs in the correct environment to ensure proper mineralization of the ECM. These studies provided evidences that EVs carry and interact with ECM molecules and have potential structural and functional roles that can be exploited for diagnostic and therapeutic purpose.

\section{Arterial Stiffening}

Lysosomes are considered advanced organelles, which are involved in many cellular processes and maintain cellular homeostasis [101, 102]. Deficiency of one of eleven lysosomal hydrolases is linked to a group of inborn errors of metabolism known as mucopolysaccharidoses (MPSs). Lysosomal accumulation of glycosaminoglycans (GAGs) due to deficiency of these lysosomal hydrolases causes multi-systemic disease, including cardiac valvular dysplasia, and arterial vascular disease [103]. In MPS patients, arterial luminal stenosis was observed to be caused by intimal medial proliferation [104]. In addition, there was significantly increased carotid intima-media thickness (CIMT) [105] in patients with MPSs than matched controls [106]. These findings were further validated by another study carried out in a pediatric cohort of MPS patients by a larger, dual-center assessment of 25 MPS Type I and II patients. The study found increased carotid artery stiffness compared to a healthy pediatric control cohort [107]. The etiology of augmented carotid stiffness in MPS patients is not only due to accumulation of GAG alone, but rather by secondary alterations of arterial parenchyma induced by accumulation of GAG. Arterial inflammation, proliferation of myofibroblasts and VSMCs, together with alterations in elastin fibrils have been detected in human MPS as well as in animal models [108-111], these events reduce vascular compliance via mechanisms mimicking the process of atherosclerosis [112].

In Fabry disease as mentioned earlier, vasculopathy is the principal clinical manifestation in this disease consisting of artery associated complications such as cerebral disease and nephropathy, but the pathophysiology is still unclear $[113,114]$. Increase of lyso-compound globotriaosylceramide (Lyso- Gb3) in Fabry patients and its storage in the arterial media and subsequent proliferation of SMCs are the first indicators among manifestations of vascular involvement and augmented intima media thickness. Vascular endothelial deposits of Lyso- Gb3 lead to the activation of the local rennin-angiotensin system, and, as a direct consequence, there is local inflammatory and oxidative response associated with increased arterial stiffness and blood pressure (BP) [115]. An in vivo study demonstrated that arteries from adult spontaneously hypertensive rats (SHRs) had reduced lysosomal acid phosphatase activity, which in turn lead to decreased autophagic activity and was associated with increased vascular stiffness in SHRs. However, treatment with trehalose, which is a non-reducing disaccharide and an established autophagy activator, decreased calcium sensitization in SHRs and decreased vascular stiffness in these rats [116]. The study revealed that trehalose caused rightward shift in the stress-strain curve and a decrease in the elastic modulus $\beta$ in mesenteric resistance arteries from SHRs. It improved mechanical properties of mesenteric resistance arteries in SHRs by reducing ECM deposition.

Pulse wave velocity (PWV) is directly correlated with arterial stiffness and inversely proportional to arterial distensibility [117]. Our study in mice demonstrated that SMC-specific overexpression of Smpd1, which converts sphingomyelin to ceramide, increased PWV in $S m p d 1^{\text {trg }} / \mathrm{SM}^{\text {cre }}$ mice even before frank aortic medial calcification can be observed. This PWV 
was further increased in Smpd1 $1^{\mathrm{trg}} / \mathrm{SM}^{\text {cre }}$ mice under Vit D-treated conditions which confirms that increased lysosomal ceramide due to overexpression of Smpd1 gene contributes to arterial stiffness [34]. Further, we observed disorganized elastic lamellae with compromised integrity in the aortic media associated with distorted junctions of the innermost and outermost layers with the formation of solid plates or sheaths disorganization in the calcified aortas of these $S m p d 1^{\mathrm{trg}} / \mathrm{SM}^{\mathrm{cre}}$ mice. In another study, we revealed that lysosomal expression of TRPML1, a product of the mouse Mcoln1 gene, contributes to the arterial stiffness [58]. Functionally, PWV, an arterial stiffening indicator, was found significantly increased in Mcoln 1\% mice with or without Vit D treatment indicating that Mcoln1 gene is associated with the arterial stiffness during the development of AMC. These data indicate that lysosomal ceramide contributed to the arterial stiffness during the development of AMC.

\section{Atherosclerosis}

Atherosclerosis is a complex multifactorial arterial disease of medium and large-size arteries. Several factors appear likely to have contributed to the acceleration of the coronary artery disease, which include hypertension, diabetes, hypercholesterolemia, smoking, tobacco consumption, central obesity, environmental factors and some genetic factors [118]. One of the original concepts for the pathogenesis of atherosclerosis was proposed by Virchow (1856), who suggested that inflammation plays a primary role in initiating the atherogenic process [119].

Atherosclerosis can be viewed as a 'response to Injury' model described by Russell Ross with lipoproteins or other risk factors as the injurious agents [120, 121]. Any kind of injury, may be it is physical, mechanical, chemical or infection may cause endothelial injury thereby, leading to endothelial dysfunction. Due to endothelial dysfunction and presence of oxidative stress, excess lipids and lipoproteins are oxidized resulting in the formation of Ox-LDL. Oxidative modification of low-density lipoprotein (LDL) and vascular inflammatory process are the two fundamental mechanisms, recognized widely to be involved in atherogenesis. In fact, cooperativity between oxidation and inflammation seems to be the key event in the development of early atherosclerotic lesions [122]. Atherosclerotic plaques are characterized by an accumulation of lipids in the arterial walls together with the infiltration of immunocytes (monocytes, T lymphocytes, neutrophils, mast cells). The up-regulation of scavenger receptors in plaque-activated macrophages are operational in the uptake of modified lipoprotein particles (mLp), which leads to their transformation into cholesterol loaded macrophage-derived foam cells as shown in Fig. 3. Accumulation of the latter within the plaque is a characteristic of fatty-streak type lesion, which ultimately may evolve to advanced fibro-lipid plaque [123]. In response to atherogenic stimuli, SMCs switch from the 'contractile' to the 'synthetic' phenotype and migrate from the vessel's media into the intima. Plaque SMCs synthesize abnormal ECM proteins, express new adhesion molecules for monocytes and lymphocytes and produce various inflammatory mediators [124]. Matrix metalloproteinases (MMPs) (a member of gelatinase family) play an important role in cellular migration and processing of ECM proteins in particular plaque instability and rupture during arterial lesion progression $[125,126]$. This section will summarize the contribution of autophagic process, redox signalosomes, cholesterol metabolism and inflammasome activation in the initiation and development of atherosclerosis.

SMC autophagy deficiency. It is well known that lysosome function is essential for autophagic process in cardiovascular cells. Strong evidence is shown that autophagy may have both protective and detrimental roles during atherosclerosis, depending upon the status of autophagy or stages of atherosclerosis [127]. Given the action of autophagy in degradation of damaged materials, it is possible that autophagy in the arterial wall may help clean up damaged components and recover cells from the damage upon atherosclerotic stimuli. In addition, autophagy activation may interfere with cell apoptosis due to engulfment of defective or damaged mitochondria by autophagosomes that limits the release of proapoptotic proteins [128-130]. On the other hand, if acute or persistent oxidative stress occurs in atherosclerosis, lysosomes may be damaged to release its hydrolases, and in this way, autophagy is engaged 


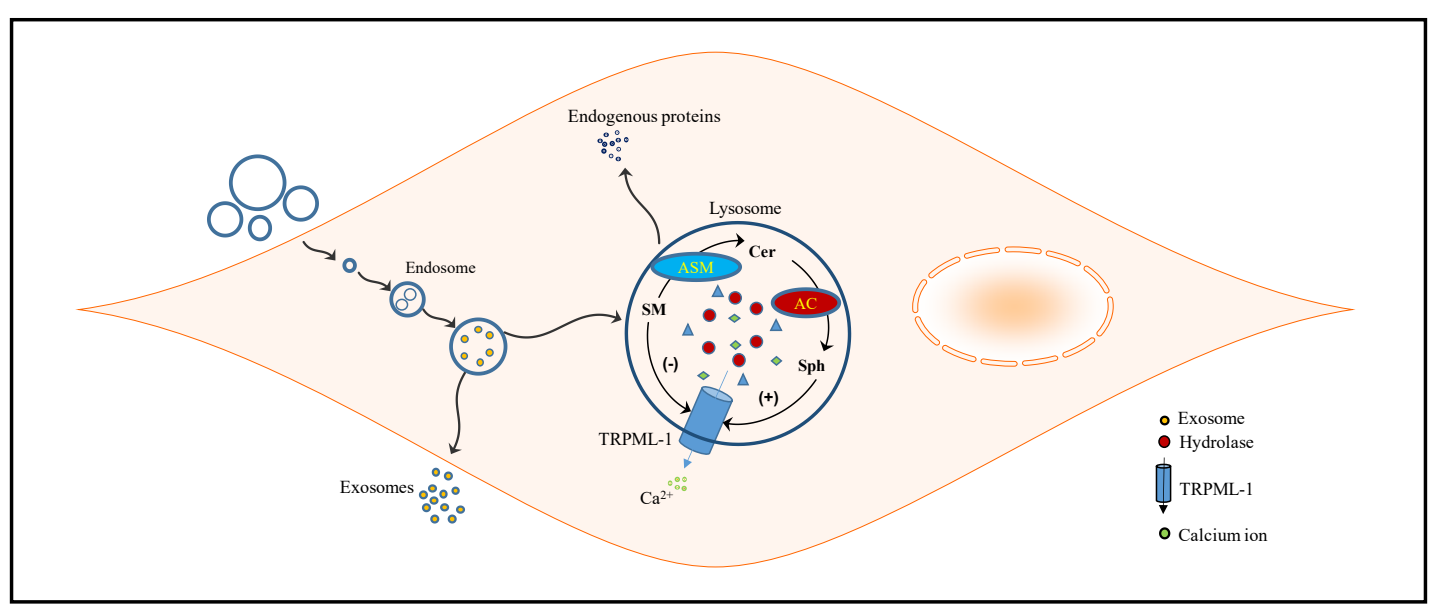

Fig. 3. Schematic model demonstrating lysosomal sphingolipid-mediated exosome secretion from SMCs during vascular calcification. Lysosomal sphingolipid metabolism regulates TRPML1-mediated $\mathrm{Ca}^{2+}$ release from lysosomes, which controls lysosome trafficking and fusion with MVBs via , and thereby controlling the fate of these MVBs. Due to deficient lysosome trafficking or fusion to MVBs, MVBs fuse with the plasma membrane, which is associated with exosome excretion in arterial SMCs during vascular calcification. SMCs: Smooth muscle cells; CER: Ceramide; SM: Sphingomyelin; ASM: Acid Sphingomyelinase; AC: Acid Ceramidase; TRPML1: Lysosomal transient receptor potential mucolipin 1; MVB: Multivesicular Body.

as part of oxidative stress enhancing the degree of cellular damage [130-132]. In addition, autophagy in different vascular cells may play different roles in atherosclerosis. For example, increased autophagic death of macrophages may possibly attenuate the foam cell formation, reducing atherosclerotic injury. However, excessive activation of autophagy in ECs may lead to damage of the endothelium enhancing atherogenic injury. In SMCs, enhanced autophagy may induce their modulation to a differentiated, quiescent, and contractile phenotype decreasing cell proliferation and preventing fibrosis. Nevertheless, excessive autophagy in SMCs may result in their death increasing the instability of atherosclerotic plaques [130, $131,133,134]$.

Our study in coronary arterial myocytes (CAMs) demonstrated that CD38 gene deletion results in an impaired autophagic flux associated with blunted NAADP/lysosomal $\mathrm{Ca}^{2+}$, dynein activation, and autophagosomes trafficking. Impaired autophagic flux promotes CAM dedifferentiation, proliferation, and growth, which stimulates ECM production thereby, contributes to coronary arterial smooth muscle remodeling accelerating atherosclerosis [135]. Furthermore, we demonstrated that impaired autophagy due to CD38 gene deletion blocks collagen I degradation in CAM, and resulted in collagen I-deposition mainly in lysosomes and autophagosomes which resulted in coronary arterial fibrosis, a characteristic feature of atherosclerosis [136]. In addition, defective autophagic flux due to deficiency of ASMase-mediated regulation of lysosome trafficking and fusion to APs in CASMCs caused imbalance of arterial smooth muscle homeostasis leading to coronary atherosclerosis during hyperlipidemia or hypercholesteremia [137]. Recently, our study showed that GDF11 blocked dedifferentiation and autophagosome accumulation in CD38 deficient CASMCs under in vitro and in vivo conditions, which is associated with reduced neointima formation in the partial ligated carotid arteries [138].

Redox signalosomes in endothelial injury. Cross talk between lysosome-membrane and membrane raft (MR) signaling platforms have been shown to regulate endothelial function and lead to endothelial injury upon pathological stimuli [18]. These MR redox-signaling platforms consist of a multiple protein complex which uses lipid rafts (LRs) or MRs as a platform to control redox signaling. Various agonists such as FasL, TNF- $\alpha$, TRIAL, endostatin, visfatin and other stimuli were found to stimulate the formation of MR clusters on the ECs 
membrane which result in the formation of endothelial redox signalosomes $[139,140]$. It has been demonstrated that NADPH oxidase (Nox) subunits clustering and its activation is central to the formation of endothelial redox signalosome [18]. In addition, there are various receptors, which may bind to agonists and stimulate the formation of signalosomes as well as molecules promoting MR platform formation and functions. In this context, ASMase has been found to be an important enzyme, which activates or facilitates the formation of MR redox signalosomes. MR redox signalosomes produce $\mathrm{O}_{2}$ and lead to redox regulation of cell and organ functions as depicted by $\mathrm{O}_{2}$ - production in isolated MR fractions from cells stimulated by FasL or other stimuli [141-143]. This Nox-derived $\mathrm{O}_{2}-$ leads to redox regulation of vascular endothelial and smooth muscle function, and excess generation of these $\mathrm{O}_{2}-$ may lead to endothelial injury promoting atherosclerosis as shown in Fig. 3 [144, 145]. In brain ECs, polychlorinated biphenyl-induced LR-dependent Nox/JAK/EGFR signaling regulates the expression of cell adhesion molecules and increases the adhesion of leukocytes to endothelial monolayers [146]. Another study reported inactivation of Nox by high-density lipoprotein (HDL), which may be via interrupting the assembly of Nox subunits at MRs that may contribute to the protective actions of HDL in vasculature against inflammationmediated oxidative damage [147].

As mentioned earlier, that lysosome dysfunction has detrimental impacts on various cellular processes and has been characterized in numerous cardiovascular diseases [15]. Our findings $[148,149]$ and others $[150,151]$ revealed that under different pathological stimuli, lysosomes are rapidly fused into the cell membrane leading to secretion of ASMase locally or attached to the surface of the cell membrane. Various danger factors act on ECs which may induce lysosomal trafficking and fusion to the cell membrane resulting in ceramide production via activation of ASMase thereby leading to formation of MR-Nox redox signaling platforms as shown in Fig. 3. Upon sustained injuries, interaction of various signaling molecules in these redox signaling platforms lead to formation of signalosomes, which produce $\mathrm{O}_{2}$ and induce endothelial dysfunction, resulting in atherogenesis [152]. Reactive oxygen species (ROS) -induced increased activation of lysosomal ASMase is known to be a key contributor for the formation of these MR-Nox redox signaling platforms. ASMase dimer formation by modification of the free C-terminal cysteine is required for enhancement of ASMase activity promoting MR platform formation [153, 154]. A study showed that selective activation of lysosomal ASMase by pharmacological intervention enhanced lysosome trafficking and fusion to the MR area on the plasma membrane in ECs [155]. Recently, our study demonstrated that acid sphingomyelin and ceramide signaling via the formation of MR redox signaling platforms induced the endothelial Nlrp3 inflammasomes formation and activation during hypocholesterolemia, which lead to endothelial dysfunction, cell phenotypic transition and vascular inflammation, and consequent atherosclerosis [156]. In another study, in cultured ECs (EOMA cells), we observed that inhibitory action of butyrate on the Nlrp3 inflammasome was attributed to a blockade of lipid raft redox signaling platforms which produce $\mathrm{O}_{2}^{-}$upon 7-ketocholesterol [7-Ket] or cholesterol crystals (CHC) stimulations [157]. Lysosomal membrane damage is another important role of lysosomes in vascular regulation. Damage to lysosomal membrane may be due to excess production or accumulation of ROS leading to alteration of the lysosomal compartments. This may prevent lysosomal fusion with autophagic vacuoles containing damaged components, and release of potent hydrolases [6]. Enhanced intracellular oxidative stress and lysosome amplification via release of lysosomal enzymes will cause cell death, which may lead to the destabilization of atherosclerotic plaques if occurring in SMCs. Destabilization of atherosclerotic plaques occurs due to the reduced synthesis of collagen and thinning of the fibrous cap. In addition, in ECs, cell death promotes lesioned thrombosis in the involved arteries [131,132].

Inflammasome activation and atherosclerosis. Among the Nod-like receptor family, the nucleotide-binding oligomerization domain (NOD)-like receptor containing pyrin domain 3 (Nlrp3) inflammasome, has been extensively characterized compared with others, which oligomerize with the adaptor molecule apoptosis-associated speck-like protein containing 
a CARD (caspase recruitment domain) (ASC), and the cysteine protease caspase- 1 to form large cytosolic multiprotein complex called Nlrp3 inflammasome [158, 159]. This cytosolic multiprotein complex Nlrp3 inflammasome is required for cleavage of pro-IL-1 $\beta$ and proIL-18 into mature IL-1 $\beta$ and IL-18 $[132,160,161]$. Various inflammatory disorders in humans may be instigated by Nlrp3 inflammasomes, including atherosclerosis [162], glomerular sclerosis [163], gouts [164], and type 2 diabetes [160].

Our laboratory over the last 10 years extensively explored the role of Nlrp3 inflammasomes in the development and progression of atherosclerosis during hyperlipidemia. In addition, we also found multiple actions of the inflammasome activation that are independent of inflammation and contribute to the development of atherosclerosis. As per literature, formation and activation of inflammasomes may be one of the crucial mechanistic pathways for many degenerative diseases such as atherosclerosis, glomerular sclerosis, Alzheimer's disease and liver cirrhosis [165-167]. Upon various pathological stimuli, endothelial dysfunction develops at an early stage of vascular disease; our laboratory investigated the redox activation of Nlrp3 inflammasomes and its implication in endothelial injury. Under in vitro conditions in ECs we demonstrated that adipokine visfatin induced the formation and activation of Nlrp3 inflammasomes mediated via membrane raft redox signaling platformderived ROS and consequent (Thioredoxin Interacting Protein) TXNIP-Nlrp3 interaction. Furthermore, in the intima of partially ligated carotid arteries, our findings revealed increased activation of endothelial Nlrp3 inflammasomes, which locally induced vascular injury and inflammation. However, caspase-1 inhibitor and ASC gene knockout or silencing completely blocked IL-1 $\beta$ production in the intima [168]. In mice fed on high-fat diet (HFD) for 6 weeks, visfatin markedly reduced the expression of tight and adhesion junction proteins and increased vascular permeability via HMGB1/ RAGE signaling in the coronary arterial endothelium leading to the onset of metabolic vasculopathy that, ultimately, results in atherosclerosis [169]. Moreover, we found that during hypercholesterolemia, impaired endothelial dysfunction is associated with endothelial Nlrp3 inflammasome activation and HMGB1 pathway accompanied with increased pyroptosis independent of IL- $1 \beta$ signaling in the ECs [170]. These results were first of its kind which revealed a novel action of endothelial inflammasomes in endothelial dysfunction independent of canonical inflammation.

In mouse carotid arterial endothelial cells (CAECs) from ASMase wild type and gene knockout mice, 7-Keto or ChC markedly increased the formation and activation of Nlrp3 inflammasomes associated with MR clustering with Nox subunits as shown by CTXB (MR marker) and gp91phox aggregation mediated via ROS-TXNIP signaling pathway. In vivo, enhanced ceramide production via ASMase result in Nlrp3 inflammasome activation which contributes to atherosclerotic lesions in the carotid arteries. The study revealed that ASMase and ceramide-associated MR clustering with Nox subunits plays a crucial role in endothelial inflammasome activation and dysfunction which induced neointima formation in the carotid arteries $[156,157]$. Recently our study under in vitro and in vivo conditions demonstrated that autophagy inhibition and associated lysosome dysfunction induced the formation and activation of Nlrp3 inflammasomes [171]. 7-Keto, a proatherogenic stimulus enhanced Nlrp3 inflammasomes formation and activation in cultured CASMCs, however rapamycin, a lysosome function and autophagy enhancer decreased the 7-Ketoinduced Nlrp3 inflammasomes formation and activation. Inhibition of autophagosome (AP) formation by spautin-1 and blockade of lysosome function by bafilomycin increased 7-Ketoinduced formation and activation of Nlrp3 inflammasomes in CASMCs from mice. In animal studies, mice having CD38 gene deletion, fed on western diet (WD) showed augmented inflammasomes formation and activation in the coronary arterial wall. Chloroquine, lysosome function inhibitor, enhanced, and rapamycin blocked WD-induced formation and activation of the Nlrp3 inflammasome in the coronary arterial wall of these mice. The study concluded that upon proatherogenic stimulations, lysosome function or autophagic process tightly regulates Nlrp3 inflammasome formation and activation thereby controlling coronary arterial inflammation and medial thickening [171]. 
Yuan et al. demonstrated that during hyperglycemia acid ceramidase (Ac) regulates the release of Nlrp3 inflammasome product IL-1 $\beta$ via exosomes. The study showed that under both in vitro and in vivo situation, Ac gene deletion significantly enhanced formation and activation of the Nlrp3 inflammasome leading to IL-1 $\beta$ production in ECs during hyperglycemia. This local inflammatory response in the ECs increases cell permeability and triggers medial thickening of coronary arteries in hyperglycemia [172]. It is conceivable that upon endogenous danger signals, activation of endothelial inflammasomes might be the initial injurious response of coronary arteries due to endothelial dysfunction, besides, the classical inflammatory injury which involves the activation and recruitment of inflammatory cells such as macrophages and T-cells and their cross talk in the arterial wall leading to atherogenesis. Hence, during endothelial dysfunction and injury, activation of endothelial inflammasomes may represent a novel early event which can be exploited as a potential therapeutic target to prevent initiation or exacerbation of atherosclerosis during obesity or hypercholesterolemia.

Abnormal macrophage cholesterol metabolism. Under normal conditions, de novo synthesis of cholesterol involves distinct trafficking pathways. Exogenously cholesterol enter into the cell via the receptor-mediated endocytosis of low-density lipoproteins (LDL) and pass through the endosomal/lysosomal compartment prior to its trafficking to the endoplasmic reticulum, the Golgi apparatus, or the plasma membrane. Binding of LDL receptor (LDLR) to its ligand LDL results in endocytosis of the receptor-ligand complex at clathrin coated pits [173]. During endocytic process, acidic environment of the endosomes catalyzes dissociation of LDL from the LDLR, LDLR peptide is recycled back to the membrane while as LDL particles are degraded into lysosomes into the lipid components and amino acids by enzymes of the vesicle. Lysosomal acid lipase (LIPA) hydrolyzed the lipid components, which are mainly cholesteryl esters, into free cholesterol [174]. Active transport of free cholesterol from lysosomes to the cytosol via lysosomal Niemann-Pick C1 (NPC1) protein plays a crucial role in the cholesterol clearance from macrophages, which may prevent the initiation of foam cell formation and development of atherosclerosis.

In macrophages, it has been proposed that during foam cell formation, lysosomal lipids accumulation has two distinct consecutive phases; the initial phase is primary accumulation of free cholesterol followed by the late phase of cholesteryl ester buildup. Furthermore, the accumulation of lysosomal cholesterol shows inhibitory effects on lysosomal V- $\mathrm{H}^{+}$-ATPase activity, increasing lysosomal $\mathrm{pH}$. This alters the conversion of esterified cholesterol into free cholesterol thereby blocking cholesterol transport out of lysosomes. This vicious cycle, which alters cholesterol metabolism and its efflux from lysosomes, precipitates in the formation of foam cells. Our study in macrophages demonstrated that NAADP, a lysosome function regulator, plays an important role in cholesterol transport from lysosomes. NAADP as a CD38-derived $\mathrm{Ca}^{2+}$ messenger lead to activation of TRPML1 and functionally promotes free cholesterol efflux out of lysosomes. The study also showed that CD38 gene deletion in macrophages resulted in lysosome dysfunction, which in turn blocks lysosome dependent free cholesterol efflux and consequent lipid deposition leading to foam cell formation and development of atherosclerosis [175]. Biochemical and histochemical studies already confirmed that the abnormal lysosomal activity was associated with the development of atherosclerosis $[176,177]$. During foam cell formation in macrophages, lipid accumulation was found within large, lipid-engorged lysosomes in both human and animal atherosclerotic lesions $[177,178]$. These pathological changes in the foam cells in macrophages during atherosclerosis mimics tissue damage observed in inherited LSD, especially, mucolipidosis type IV $[179,180]$ and Niemann-Pick type C1 (NPC1) diseases [181], both of these LSD's are characterized by accumulation of lipids in lysosomes or cytosol of macrophages or arterial wall. Therefore, the mechanisms responsible for lysosomal storage diseases such as malfunctioning of lysosomal enzymes or transporters, were considered to be similar to that of the molecular basis involved in macrophage foam cell formation and development of atherosclerosis [176]. 


\section{Cellular Physiology Cell Physiol Biochem 2021;55:277-300 \begin{tabular}{l|l|l|l} 
DOl: $10.33594 / 000000373$ & O 2021 The Author(s). Published by \\
and Biochemistry & Published online: 22 May 2021 & Cell Physio Biochem Press GmbH\&co $k G$ \\
\hline
\end{tabular} \\ Bhat et al.: Lysosome and Cardiovascular Diseases}

\section{Conclusion}

In this review, we summarized the roles of lysosomes in cardiovascular diseases, in particular, in vascular calcification, arterial stiffening, and atherosclerosis. Data provided by recent studies have greatly increased our knowledge of how dysregulation of lysosomal pathways in the cardiovascular system contributes to associated diseases. Vascular calcification is a disease caused by deposition of dispersed punctate or hydroxyapatite patchy crystals, which display phenotypic switch in arterial SMCs. Current and future research about the role of lysosomes in the pathogenesis of vascular calcification would introduce newer site-specific compounds, which may prevent the incidence and the consequences of the catastrophic manifestation of arterial medial calcification. Furthermore, we discussed the new insights into the molecular mechanisms of vascular calcification, especially the role of lysosomes in the development and progression of arterial medial calcification. Moreover, alterations in sphingolipid metabolism, in particular, lysosomal-sphingolipid metabolism influence major biological processes such as biogenesis and secretion of exosomes. This alteration in lysosomal-sphingolipid metabolism may lead to lysosome dysfunction that may prevent the fusion of multivesicular bodies with lysosomes, thereby increasing exosome secretion, which has been implicated in the development of arterial medial calcification. These exosomes also play a prominent role in the phenotypic switch of arterial medial SMCs inducing the arterial stiffness and arterial medial calcification.

Even though the basic mechanistic pathways of autophagy and various autophagyrelated genes have been well studied, there are still many challenges for their translational approach. In this review, we also discussed how autophagy abnormality plays a crucial role in the atherosclerotic process. However, the role of autophagic pathways in atherosclerosis needs to be further explored, which will help to develop the different pharmacological approaches for stabilizing vulnerable and rupture-prone plaques. Moreover, fine-tuning the lysosome-exosome pathway can be exploited for novel therapeutic strategies in cardiovascular diseases such as vascular calcification and atherosclerosis. Nonetheless, lysosomal dysfunction significantly contributes to disease pathogenesis and therefore may represent an important target for future therapeutics. A deeper understanding of pathophysiology of lysosomal-exosome pathways might reduce the burden of cardiovascular disease worldwide.

\section{Acknowledgements}

Most of the works cited in this review from authors' laboratories were supported by grants from the National Institutes of Health (HL057244, HL075316 and DK120491).

\section{Disclosure Statement}

The authors have no conflicts of interests to disclose.

\section{References}

1 Christensen KA, Myers JT, Swanson JA: pH-dependent regulation of lysosomal calcium in macrophages. J Cell Sci 2002;115:599-607.

2 Churchill GC, Okada Y, Thomas JM, Genazzani AA, Patel S, Galione A: NAADP mobilizes Ca(2+) from reserve granules, lysosome-related organelles, in sea urchin eggs. Cell 2002;111:703-708.

3 Lawrence RE, Zoncu R: The lysosome as a cellular centre for signalling, metabolism and quality control. Nat Cell Biol 2019;21:133-142. 


\section{Cellular Physiology Cell Physiol Biochem 2021;55:277-300 \begin{tabular}{ll|l} 
and Biochemistry & $\begin{array}{l}\text { DOl: 10.33594/000000373 } \\
\text { Published online: } 22 \text { May } 2021\end{array}$ & $\begin{array}{l}\text { O 2021 The Author(s). Published by } \\
\text { Cell Physiol Biochem Press GmbH\&Co. KG }\end{array}$ \\
\cline { 2 - 3 }
\end{tabular} \\ Bhat et al.: Lysosome and Cardiovascular Diseases}

4 Settembre C, Fraldi A, Medina DL, Ballabio A: Signals from the lysosome: a control centre for cellular clearance and energy metabolism. Nat Rev Mol Cell Biol 2013;14:283-296.

5 Jha KN, Kameshwari DB, Shivaji S: Role of signaling pathways in regulating the capacitation of mammalian spermatozoa. Cell Mol Biol (Noisy-le-grand) 2003;49:329-340.

6 Ravikumar B, Sarkar S, Davies JE, Futter M, Garcia-Arencibia M, Green-Thompson ZW, Jimenez-Sanchez M, Korolchuk VI, Lichtenberg M, Luo S, Massey DC, Menzies FM, Moreau K, Narayanan U, Renna M, Siddiqi FH, Underwood BR, Winslow AR, Rubinsztein DC: Regulation of mammalian autophagy in physiology and pathophysiology. Physiol Rev 2010;90:1383-1435.

7 Levine B, Kroemer G: Autophagy in the pathogenesis of disease. Cell 2008;132:27-42.

8 Levine B, Klionsky DJ: Development by self-digestion: molecular mechanisms and biological functions of autophagy. Dev Cell 2004;6:463-477.

9 Wang W, Xu J, Kirsch T: Annexin-mediated Ca2+ influx regulates growth plate chondrocyte maturation and apoptosis. J Biol Chem 2003;278:3762-3769.

10 Reggiori F, Klionsky DJ: Autophagy in the eukaryotic cell. Eukaryot Cell 2002;1:11-21.

11 Xu M, Zhang Y, Xia M, Li XX, Ritter JK, Zhang F, Li PL: NAD(P)H oxidase-dependent intracellular and extracellular 02*- production in coronary arterial myocytes from CD38 knockout mice. Free Radic Biol Med 2012;52:357-365.

12 Winchester B, Vellodi A, Young E: The molecular basis of lysosomal storage diseases and their treatment. Biochem Soc Trans 2000;28:150-154.

13 Karen JK, Hale EK, Ma L: Angiokeratoma corporis diffusum (Fabry disease). Dermatol Online J 2005;11:8.

14 Ballabio A, Gieselmann V: Lysosomal disorders: from storage to cellular damage. Biochim Biophys Acta 2009;1793:684-696.

15 Wang X, Robbins J: Proteasomal and lysosomal protein degradation and heart disease. J Mol Cell Cardiol 2014;71:16-24.

16 Evans TD, Jeong SJ, Zhang X, Sergin I, Razani B: TFEB and trehalose drive the macrophage autophagylysosome system to protect against atherosclerosis. Autophagy 2018;14:724-726.

17 Chi C, Leonard A, Knight WE, Beussman KM, Zhao Y, Cao Y, Londono P, Aune E, Trembley MA, Small EM, Jeong MY, Walker LA, Xu H, Sniadecki NJ, Taylor MR, Buttrick PM, Song K: LAMP-2B regulates human cardiomyocyte function by mediating autophagosome-lysosome fusion. Proc Natl Acad Sci U S A 2019;116:556-565.

18 Zhang AY, Yi F, Zhang G, Gulbins E, Li PL: Lipid raft clustering and redox signaling platform formation in coronary arterial endothelial cells. Hypertension 2006;47:74-80.

19 Benjamin EJ, Virani SS, Callaway CW, Chamberlain AM, Chang AR, Cheng S, Chiuve SE, Cushman M, Delling FN, Deo R, de Ferranti SD, Ferguson JF, Fornage M, Gillespie C, Isasi CR, Jimenez MC, Jordan LC, Judd SE, Lackland D, Lichtman JH, et al.: Heart Disease and Stroke Statistics-2018 Update: A Report From the American Heart Association. Circulation 2018;137:e67-e492.

20 Sage AP, Tintut Y, Demer LL: Regulatory mechanisms in vascular calcification. Nat Rev Cardiol 2010;7:528536.

21 Otsuka F, Sakakura K, Yahagi K, Joner M, Virmani R: Has our understanding of calcification in human coronary atherosclerosis progressed? Arterioscler Thromb Vasc Biol 2014;34:724-736.

22 Bostrom KI, Rajamannan NM, Towler DA: The regulation of valvular and vascular sclerosis by osteogenic morphogens. Circ Res 2011;109:564-577.

23 Shanahan CM, Cary NR, Salisbury JR, Proudfoot D, Weissberg PL, Edmonds ME: Medial localization of mineralization-regulating proteins in association with Monckeberg's sclerosis: evidence for smooth muscle cell-mediated vascular calcification. Circulation 1999;100:2168-2176.

24 Proudfoot D, Skepper JN, Hegyi L, Bennett MR, Shanahan CM, Weissberg PL: Apoptosis regulates human vascular calcification in vitro: evidence for initiation of vascular calcification by apoptotic bodies. Circ Res 2000;87:1055-1062.

25 Kapustin AN, Chatrou ML, Drozdov I, Zheng Y, Davidson SM, Soong D, Furmanik M, Sanchis P, De Rosales RT, Alvarez-Hernandez D, Shroff R, Yin X, Muller K, Skepper JN, Mayr M, Reutelingsperger CP, Chester A, Bertazzo S, Schurgers LJ, Shanahan CM: Vascular smooth muscle cell calcification is mediated by regulated exosome secretion. Circ Res 2015;116:1312-1323. 


\section{Cellular Physiology Cell Physiol Biochem 2021;55:277-300 \begin{tabular}{ll|l} 
and Biochemistry $10.33594 / 000000373$ & $\begin{array}{l}\text { Published online: } 22 \text { May } 2021 \\
\text { Pell Physiol Biochem Press GmbH\&Co. KG }\end{array}$ \\
\hline
\end{tabular} \\ Bhat et al.: Lysosome and Cardiovascular Diseases}

26 Morris TG, Borland SJ, Clarke CJ, Wilson C, Hannun YA, Ohanian V, Canfield AE, Ohanian J: Sphingosine 1-phosphate activation of ERM contributes to vascular calcification. J Lipid Res 2018;59:69-78.

27 Fernandez-Pisonero I, Lopez J, Onecha E, Duenas AI, Maeso P, Crespo MS, San Roman JA, Garcia-Rodriguez C: Synergy between sphingosine 1-phosphate and lipopolysaccharide signaling promotes an inflammatory, angiogenic and osteogenic response in human aortic valve interstitial cells. PLoS One 2014;9:e109081.

28 Son DJ, Jung YY, Seo YS, Park H, Lee DH, Kim S, Roh YS, Han SB, Yoon DY, Hong JT: Interleukin-32alpha Inhibits Endothelial Inflammation, Vascular Smooth Muscle Cell Activation, and Atherosclerosis by Upregulating Timp3 and Reck through suppressing microRNA-205 Biogenesis. Theranostics 2017;7:21862203.

29 Yin YJ, Zhang Q Yang YX, Yang SK, Wang HF, Shi JX, Wang ZM, Yang YH, Lin Y, Li ZY, Yang YR: [Study of the genes correlated with cyst calcification in patients with cystic echinococcosis]. Zhonghua Yu Fang Yi Xue Za Zhi 2016;50:434-438.

30 Liao L, Zhou Q Song Y, Wu W, Yu H, Wang S, Chen Y, Ye M, Lu L: Ceramide mediates Ox-LDL-induced human vascular smooth muscle cell calcification via p38 mitogen-activated protein kinase signaling. PLoS One 2013;8:e82379.

31 Janecke AR, Xu R, Steichen-Gersdorf E, Waldegger S, Entenmann A, Giner T, Krainer I, Huber LA, Hess MW, Frishberg Y, Barash H, Tzur S, Schreyer-Shafir N, Sukenik-Halevy R, Zehavi T, Raas-Rothschild A, Mao C, Muller T: Deficiency of the sphingosine-1-phosphate lyase SGPL1 is associated with congenital nephrotic syndrome and congenital adrenal calcifications. Hum Mutat 2017;38:365-372.

32 Djekic D, Pinto R, Repsilber D, Hyotylainen T, Henein M: Serum untargeted lipidomic profiling reveals dysfunction of phospholipid metabolism in subclinical coronary artery disease. Vasc Health Risk Manag 2019;15:123-135.

33 Bhat OM, Li G, Yuan X, Huang D, Gulbins E, Kukreja RC, Li PL: Arterial Medial Calcification through Enhanced small Extracellular Vesicle Release in Smooth Muscle-Specific Asah1 Gene Knockout Mice. Sci Rep 2020;10:1645.

34 Bhat OM, Yuan X, Cain C, Salloum FN, Li PL: Medial calcification in the arterial wall of smooth muscle cellspecific Smpd1 transgenic mice: A ceramide-mediated vasculopathy. J Cell Mol Med 2020;24:539-553.

35 Yoshida T, Owens GK: Molecular determinants of vascular smooth muscle cell diversity. Circ Res 2005;96:280-291.

36 Owens GK, Kumar MS, Wamhoff BR: Molecular regulation of vascular smooth muscle cell differentiation in development and disease. Physiol Rev 2004;84:767-801.

37 Chistiakov DA, Orekhov AN, Bobryshev YV: Vascular smooth muscle cell in atherosclerosis. Acta Physiol (Oxf) 2015;214:33-50.

38 Bennett MR, Sinha S, Owens GK: Vascular Smooth Muscle Cells in Atherosclerosis. Circ Res 2016;118:692702.

39 Davis-Dusenbery BN, Wu C, Hata A: Micromanaging vascular smooth muscle cell differentiation and phenotypic modulation. Arterioscler Thromb Vasc Biol 2011;31:2370-2377.

40 Rangrez AY, Massy ZA, Metzinger-Le Meuth V, Metzinger L: miR-143 and miR-145: molecular keys to switch the phenotype of vascular smooth muscle cells. Circ Cardiovasc Genet 2011;4:197-205.

41 Bodine PV, Komm BS: Wnt signaling and osteoblastogenesis. Rev Endocr Metab Disord 2006;7:33-39.

42 Al-Aly Z, Shao JS, Lai CF, Huang E, Cai J, Behrmann A, Cheng SL, Towler DA: Aortic Msx2-Wnt calcification cascade is regulated by TNF-alpha-dependent signals in diabetic Ldlr-/- mice. Arterioscler Thromb Vasc Biol 2007;27:2589-2596.

43 Lian JB, Stein GS, Javed A, van Wijnen AJ, Stein JL, Montecino M, Hassan MQ, Gaur T, Lengner CJ, Young DW: Networks and hubs for the transcriptional control of osteoblastogenesis. Rev Endocr Metab Disord 2006;7:1-16.

44 Nakashima K, Zhou X, Kunkel G, Zhang Z, Deng JM, Behringer RR, de Crombrugghe B: The novel zinc fingercontaining transcription factor osterix is required for osteoblast differentiation and bone formation. Cell 2002;108:17-29.

45 Zhu F, Friedman MS, Luo W, Woolf P, Hankenson KD: The transcription factor osterix (SP7) regulates BMP6induced human osteoblast differentiation. J Cell Physiol 2012;227:2677-2685.

46 Yang H, Curinga G, Giachelli CM: Elevated extracellular calcium levels induce smooth muscle cell matrix mineralization in vitro. Kidney Int 2004;66:2293-2299. 


\section{Cellular Physiology Cell Physiol Biochem 2021;55:277-300 \begin{tabular}{ll|l} 
and Biochemistry & $\begin{array}{l}\text { DOl: 10.33594/000000373 } \\
\text { Published online: } 22 \text { May } 2021\end{array}$ & $\begin{array}{l}\text { O 2021 The Author(s). Published by } \\
\text { Cell Physiol Biochem Press GmbH\&Co. KG }\end{array}$ \\
\cline { 2 - 3 }
\end{tabular} \\ Bhat et al.: Lysosome and Cardiovascular Diseases}

47 Steitz SA, Speer MY, Curinga G, Yang HY, Haynes P, Aebersold R, Schinke T, Karsenty G, Giachelli CM: Smooth muscle cell phenotypic transition associated with calcification: upregulation of $\mathrm{Cbfa} 1$ and downregulation of smooth muscle lineage markers. Circ Res 2001;89:1147-1154.

48 Chen NX, O'Neill KD, Duan D, Moe SM: Phosphorus and uremic serum up-regulate osteopontin expression in vascular smooth muscle cells. Kidney Int 2002;62:1724-1731.

49 Speer MY, Yang HY, Brabb T, Leaf E, Look A, Lin WL, Frutkin A, Dichek D, Giachelli CM: Smooth muscle cells give rise to osteochondrogenic precursors and chondrocytes in calcifying arteries. Circ Res 2009;104:733741.

50 Cozzolino M, Dusso AS, Slatopolsky E: Role of calcium-phosphate product and bone-associated proteins on vascular calcification in renal failure. J Am Soc Nephrol 2001;12:2511-2516.

51 Moe SM, O’Neill KD, Duan D, Ahmed S, Chen NX, Leapman SB, Fineberg N, Kopecky K: Medial artery calcification in ESRD patients is associated with deposition of bone matrix proteins. Kidney Int 2002;61:638-647.

52 Moe SM, Duan D, Doehle BP, O'Neill KD, Chen NX: Uremia induces the osteoblast differentiation factor Cbfa1 in human blood vessels. Kidney Int 2003;63:1003-1011.

53 London GM, Guerin AP, Marchais SJ, Metivier F, Pannier B, Adda H: Arterial media calcification in end-stage renal disease: impact on all-cause and cardiovascular mortality. Nephrol Dial Transplant 2003;18:17311740.

54 Serban KA, Rezania S, Petrusca DN, Poirier C, Cao D, Justice MJ, Patel M, Tsvetkova I, Kamocki K, Mikosz A, Schweitzer KS, Jacobson S, Cardoso A, Carlesso N, Hubbard WC, Kechris K, Dragnea B, Berdyshev EV, McClintock J, Petrache I: Structural and functional characterization of endothelial microparticles released by cigarette smoke. Sci Rep 2016;6:31596.

55 Goldsmith DJ, Covic A, Sambrook PA, Ackrill P: Vascular calcification in long-term haemodialysis patients in a single unit: a retrospective analysis. Nephron 1997;77:37-43.

56 Kang YH, Jin JS, Yi DW, Son SM: Bone morphogenetic protein-7 inhibits vascular calcification induced by high vitamin D in mice. Tohoku J Exp Med 2010;221:299-307.

57 Bas A, Lopez I, Perez J, Rodriguez M, Aguilera-Tejero E: Reversibility of calcitriol-induced medial artery calcification in rats with intact renal function. J Bone Miner Res 2006;21:484-490.

58 Bhat OM, Yuan X, Camus S, Salloum FN, Li PL: Abnormal Lysosomal Positioning and Small Extracellular Vesicle Secretion in Arterial Stiffening and Calcification of Mice Lacking Mucolipin 1 Gene. Int J Mol Sci 2020;21:1713.

59 Cai Y, Wang XL, Flores AM, Lin T, Guzman RJ: Inhibition of endo-lysosomal function exacerbates vascular calcification. Sci Rep 2018;8:3377.

60 Lotvall J, Hill AF, Hochberg F, Buzas EI, Di Vizio D, Gardiner C, Gho YS, Kurochkin IV, Mathivanan S, Quesenberry P, Sahoo S, Tahara H, Wauben MH, Witwer KW, Thery C: Minimal experimental requirements for definition of extracellular vesicles and their functions: a position statement from the International Society for Extracellular Vesicles. J Extracell Vesicles 2014;3:26913.

61 Al-Nedawi K, Meehan B, Rak J: Microvesicles: messengers and mediators of tumor progression. Cell Cycle 2009;8:2014-2018.

62 Sotelo JR, Porter KR: An electron microscope study of the rat ovum. J Biophys Biochem Cytol 1959;5:327342.

63 Akers JC, Gonda D, Kim R, Carter BS, Chen CC: Biogenesis of extracellular vesicles (EV): exosomes, microvesicles, retrovirus-like vesicles, and apoptotic bodies. J Neurooncol 2013;113:1-11.

64 Boulanger CM, Loyer X, Rautou PE, Amabile N: Extracellular vesicles in coronary artery disease. Nat Rev Cardiol 2017;14:259-272.

65 Tetta C, Ghigo E, Silengo L, Deregibus MC, Camussi G: Extracellular vesicles as an emerging mechanism of cell-to-cell communication. Endocrine 2013;44:11-19.

66 van Rooij E, Olson EN: MicroRNA therapeutics for cardiovascular disease: opportunities and obstacles. Nat Rev Drug Discov 2012;11:860-872.

67 Aikawa E: Extracellular vesicles in cardiovascular disease: focus on vascular calcification. J Physiol 2016;594:2877-2880.

68 Hutcheson JD, Goettsch C, Bertazzo S, Maldonado N, Ruiz JL, Goh W, Yabusaki K, Faits T, Bouten C, Franck G, Quillard T, Libby P, Aikawa M, Weinbaum S, Aikawa E: Genesis and growth of extracellular-vesicle-derived microcalcification in atherosclerotic plaques. Nat Mater 2016;15:335-343. 


\section{Cellular Physiology Cell Physiol Biochem 2021;55:277-300

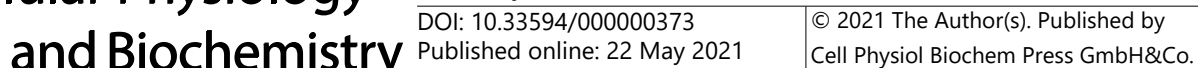 \\ Bhat et al.: Lysosome and Cardiovascular Diseases}

69 Oggero S, Austin-Williams S, Norling LV: The Contrasting Role of Extracellular Vesicles in Vascular Inflammation and Tissue Repair. Front Pharmacol 2019;10:1479.

70 Buendia P, Montes de Oca A, Madueno JA, Merino A, Martin-Malo A, Aljama P, Ramirez R, Rodriguez M, Carracedo J: Endothelial microparticles mediate inflammation-induced vascular calcification. FASEB J 2015;29:173-181.

71 Ikeda K, Souma Y, Akakabe Y, Kitamura Y, Matsuo K, Shimoda Y, Ueyama T, Matoba S, Yamada H, Okigaki M, Matsubara H: Macrophages play a unique role in the plaque calcification by enhancing the osteogenic signals exerted by vascular smooth muscle cells. Biochem Biophys Res Commun 2012;425:39-44.

72 New SE, Goettsch C, Aikawa M, Marchini JF, Shibasaki M, Yabusaki K, Libby P, Shanahan CM, Croce K, Aikawa E: Macrophage-derived matrix vesicles: an alternative novel mechanism for microcalcification in atherosclerotic plaques. Circ Res 2013;113:72-77.

73 Alique M, Ruiz-Torres MP, Bodega G, Noci MV, Troyano N, Bohorquez L, Luna C, Luque R, Carmona A, Carracedo J, Ramirez R: Microvesicles from the plasma of elderly subjects and from senescent endothelial cells promote vascular calcification. Aging (Albany NY) 2017;9:778-789.

74 Jansen F, Xiang X, Werner N: Role and function of extracellular vesicles in calcific aortic valve disease. Eur Heart J 2017;38:2714-2716.

75 Deng L, Blanco FJ, Stevens H, Lu R, Caudrillier A, McBride M, McClure JD, Grant J, Thomas M, Frid M, Stenmark K, White K, Seto AG, Morrell NW, Bradshaw AC, MacLean MR, Baker AH: MicroRNA-143 Activation Regulates Smooth Muscle and Endothelial Cell Crosstalk in Pulmonary Arterial Hypertension. Circ Res 2015;117:870-883.

76 Trajkovic K, Hsu C, Chiantia S, Rajendran L, Wenzel D, Wieland F, Schwille P, Brugger B, Simons M: Ceramide triggers budding of exosome vesicles into multivesicular endosomes. Science 2008;319:1244-1247.

77 Reynolds JL, Skepper JN, McNair R, Kasama T, Gupta K, Weissberg PL, Jahnen-Dechent W, Shanahan CM: Multifunctional roles for serum protein fetuin-a in inhibition of human vascular smooth muscle cell calcification. J Am Soc Nephrol 2005;16:2920-2930.

78 Kapustin AN, Davies JD, Reynolds JL, McNair R, Jones GT, Sidibe A, Schurgers LJ, Skepper JN, Proudfoot D, Mayr M, Shanahan CM: Calcium regulates key components of vascular smooth muscle cell-derived matrix vesicles to enhance mineralization. Circ Res 2011;109:e1-12.

79 Shroff RC, Shah V, Hiorns MP, Schoppet M, Hofbauer LC, Hawa G, Schurgers LJ, Singhal A, Merryweather I, Brogan P, Shanahan C, Deanfield J, Rees L: The circulating calcification inhibitors, fetuin-A and osteoprotegerin, but not matrix Gla protein, are associated with vascular stiffness and calcification in children on dialysis. Nephrol Dial Transplant 2008;23:3263-3271.

80 Goettsch C, Hutcheson JD, Aikawa M, Iwata H, Pham T, Nykjaer A, Kjolby M, Rogers M, Michel T, Shibasaki M, Hagita S, Kramann R, Rader DJ, Libby P, Singh SA, Aikawa E: Sortilin mediates vascular calcification via its recruitment into extracellular vesicles. J Clin Invest 2016;126:1323-1336.

81 Chae YM, Heo SH, Kim JY, Lee JM, Ryoo HM, Cho JY: Upregulation of smpd3 via BMP2 stimulation and Runx2. BMB Rep 2009;42:86-90.

82 Kakoi H, Maeda S, Shinohara N, Matsuyama K, Imamura K, Kawamura I, Nagano S, Setoguchi T, Yokouchi M, Ishidou Y, Komiya S: Bone morphogenic protein (BMP) signaling up-regulates neutral sphingomyelinase 2 to suppress chondrocyte maturation via the Akt protein signaling pathway as a negative feedback mechanism. J Biol Chem 2014;289:8135-8150.

83 Leroyer AS, Isobe H, Leseche G, Castier Y, Wassef M, Mallat Z, Binder BR, Tedgui A, Boulanger CM: Cellular origins and thrombogenic activity of microparticles isolated from human atherosclerotic plaques. J Am Coll Cardiol 2007;49:772-777.

84 Kapustin AN, Schoppet M, Schurgers LJ, Reynolds JL, McNair R, Heiss A, Jahnen-Dechent W, Hackeng TM, Schlieper G, Harrison P, Shanahan CM: Prothrombin Loading of Vascular Smooth Muscle Cell-Derived Exosomes Regulates Coagulation and Calcification. Arterioscler Thromb Vasc Biol 2017;37:e22-e32.

85 Thompson CA, Purushothaman A, Ramani VC, Vlodavsky I, Sanderson RD: Heparanase regulates secretion, composition, and function of tumor cell-derived exosomes. J Biol Chem 2013;288:10093-10099.

86 Li C, Cui Y, Luan J, Zhou X, Li H, Wang H, Shi L, Han J: Tenascin C affects mineralization of SaOS2 osteoblastlike cells through matrix vesicles. Drug Discov Ther 2016;10:82-87.

87 de Jong OG, van Balkom BW, Gremmels H, Verhaar MC: Exosomes from hypoxic endothelial cells have increased collagen crosslinking activity through up-regulation of lysyl oxidase-like 2. J Cell Mol Med 2016;20:342-350. 


\section{Cellular Physiology Cell Physiol Biochem 2021;55:277-300 \begin{tabular}{ll|l} 
and Biochemisty $\begin{array}{l}\text { DOI 10.33594/000000373 } \\
\text { Published online: } 22 \text { May } 2021\end{array}$ & $\begin{array}{l}\text { C } 2021 \text { The Author(s). Published by } \\
\text { Cell Physiol Biochem Press GmbH\&Co. KG }\end{array}$ \\
\hline
\end{tabular} \\ Bhat et al.: Lysosome and Cardiovascular Diseases}

$88 \mathrm{Mu}$ W, Rana S, Zoller M: Host matrix modulation by tumor exosomes promotes motility and invasiveness. Neoplasia (New York, NY) 2013;15:875-887.

89 Sung BH, Ketova T, Hoshino D, Zijlstra A, Weaver AM: Directional cell movement through tissues is controlled by exosome secretion. Nat Commun 2015;6:7164.

90 Dolo V, D’Ascenzo S, Violini S, Pompucci L, Festuccia C, Ginestra A, Vittorelli ML, Canevari S, Pavan A: Matrixdegrading proteinases are shed in membrane vesicles by ovarian cancer cells in vivo and in vitro. Clin Exp Metastasis 1999;17:131-140.

91 D’Souza-Schorey C, Clancy JW: Tumor-derived microvesicles: shedding light on novel microenvironment modulators and prospective cancer biomarkers. Genes Dev 2012;26:1287-1299.

92 Gerlach JQ, Griffin MD: Getting to know the extracellular vesicle glycome. Mol Biosyst 2016;12:1071-1081.

93 Schmidt JR, Kliemt S, Preissler C, Moeller S, von Bergen M, Hempel U, Kalkhof S: Osteoblast-released Matrix Vesicles, Regulation of Activity and Composition by Sulfated and Non-sulfated Glycosaminoglycans. Mol Cell Proteomics 2016;15:558-572.

94 Wu LN, Genge BR, Wuthier RE: Association between proteoglycans and matrix vesicles in the extracellular matrix of growth plate cartilage. J Biol Chem 1991;266:1187-1194.

95 Rilla K, Pasonen-Seppanen S, Deen AJ, Koistinen VVT, Wojciechowski S, Oikari S, Karna R, Bart G, Torronen K, Tammi RH, Tammi MI: Hyaluronan production enhances shedding of plasma membrane-derived microvesicles. Exp Cell Res 2013;319:2006-2018.

96 Christianson HC, Svensson KJ, van Kuppevelt TH, Li JP, Belting M: Cancer cell exosomes depend on cellsurface heparan sulfate proteoglycans for their internalization and functional activity. Proc Natl Acad Sci U S A 2013;110:17380-17385.

97 Thompson CA, Purushothaman A, Ramani VC, Vlodavsky I, Sanderson RD: Heparanase regulates secretion, composition, and function of tumor cell-derived exosomes. J Biol Chem 2013;288:10093-10099.

98 Genge BR, Wu LN, Wuthier RE: Identification of phospholipid-dependent calcium-binding proteins as constituents of matrix vesicles. J Biol Chem 1989;264:10917-10921.

99 New SE, Aikawa E: Role of extracellular vesicles in de novo mineralization: an additional novel mechanism of cardiovascular calcification. Arterioscler Thromb Vasc Biol 2013;33:1753-1758.

100 Kirsch T, Pfaffle M: Selective binding of anchorin CII (annexin V) to type II and X collagen and to chondrocalcin (C-propeptide of type II collagen). Implications for anchoring function between matrix vesicles and matrix proteins. FEBS Lett 1992;310:143-147.

101 Appelqvist H, Waster P, Kagedal K, Ollinger K: The lysosome: from waste bag to potential therapeutic target. J Mol Cell Biol 2013;5:214-226.

102 Appelmans F, Wattiaux R, De Duve C: Tissue fractionation studies. 5. The association of acid phosphatase with a special class of cytoplasmic granules in rat liver. Biochem J 1955;59:438-445.

103 Ferreira CR, Gahl WA: Lysosomal storage diseases. Transl Sci Rare Dis 2017;2:1-71.

104 Braunlin E, Orchard PJ, Whitley CB, Schroeder L, Reed RC, Manivel JC: Unexpected coronary artery findings in mucopolysaccharidosis. Report of four cases and literature review. Cardiovasc Pathol 2014;23:145-151.

105 Wendelhag I, Gustavsson T, Suurkula M, Berglund G, Wikstrand J: Ultrasound measurement of wall thickness in the carotid artery: fundamental principles and description of a computerized analysing system. Clin Physiol 1991;11:565-577.

106 Wang RY, Covault KK, Halcrow EM, Gardner AJ, Cao X, Newcomb RL, Dauben RD, Chang AC: Carotid intimamedia thickness is increased in patients with mucopolysaccharidoses. Mol Genet Metab 2011;104:592-596.

107 Wang RY, Braunlin EA, Rudser KD, Dengel DR, Metzig AM, Covault KK, Polgreen LE, Shapiro E, Steinberger J, Kelly AS: Carotid intima-media thickness is increased in patients with treated mucopolysaccharidosis types I and II, and correlates with arterial stiffness. Mol Genet Metab 2014;111:128-132.

108 Metcalf JA, Linders B, Wu S, Bigg P, O’Donnell P, Sleeper MM, Whyte MP, Haskins M, Ponder KP: Upregulation of elastase activity in aorta in mucopolysaccharidosis I and VII dogs may be due to increased cytokine expression. Mol Genet Metab 2010;99:396-407.

109 Lyons JA, Dickson PI, Wall JS, Passage MB, Ellinwood NM, Kakkis ED, McEntee MF: Arterial pathology in canine mucopolysaccharidosis-I and response to therapy. Lab Invest 2011;91:665-674.

110 Khalid O, Vera MU, Gordts PL, Ellinwood NM, Schwartz PH, Dickson PI, Esko JD, Wang RY: Immune-Mediated Inflammation May Contribute to the Pathogenesis of Cardiovascular Disease in Mucopolysaccharidosis Type I. PLoS One 2016;11:e0150850. 


\section{Cellular Physiology Cell Physiol Biochem 2021;55:277-300

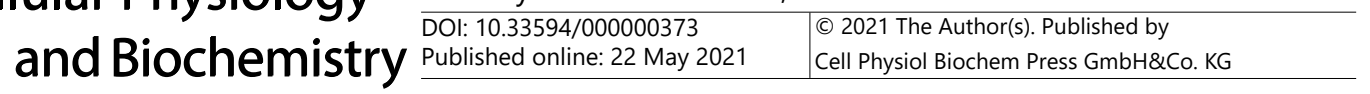 \\ Bhat et al.: Lysosome and Cardiovascular Diseases}

111 Simonaro CM, Tomatsu S, Sikora T, Kubaski F, Frohbergh M, Guevara JM, Wang RY, Vera M, Kang JL, Smith LJ, Schuchman EH, Haskins ME: Pentosan Polysulfate: Oral Versus Subcutaneous Injection in Mucopolysaccharidosis Type I Dogs. PLoS One 2016;11:e0153136.

112 Syeda B, Gottsauner-Wolf M, Denk S, Pichler P, Khorsand A, Glogar D: Arterial compliance: a diagnostic marker for atherosclerotic plaque burden? Am J Hypertens 2003;16:356-362.

113 Brady RO, Gal AE, Bradley RM, Martensson E, Warshaw AL, Laster L: Enzymatic defect in Fabry's disease. Ceramidetrihexosidase deficiency. N Engl J Med 1967;276:1163-1167.

114 Kint JA: Fabry's disease: alpha-galactosidase deficiency. Science 1970;167:1268-1269.

115 Rombach SM, Twickler TB, Aerts JM, Linthorst GE, Wijburg FA, Hollak CE: Vasculopathy in patients with Fabry disease: current controversies and research directions. Mol Genet Metab 2010;99:99-108.

116 McCarthy CG, Wenceslau CF, Calmasini FB, Klee NS, Brands MW, Joe B, Webb RC: Reconstitution of autophagy ameliorates vascular function and arterial stiffening in spontaneously hypertensive rats. Am J Physiol Heart Circ Physiol 2019;317:H1013-H1027.

117 Lane HA, Smith JC, Davies JS: Noninvasive assessment of preclinical atherosclerosis. Vasc Health Risk Manag 2006;2:19-30.

118 Mallika V, Goswami B, Rajappa M: Atherosclerosis pathophysiology and the role of novel risk factors: a clinicobiochemical perspective. Angiology 2007;58:513-522.

119 Goldstein JL, Brown MS: Atherosclerosis: the low-density lipoprotein receptor hypothesis. Metabolism 1977;26:1257-1275.

120 Ross R: The pathogenesis of atherosclerosis: a perspective for the 1990s. Nature 1993;362:801-809.

121 Libby P, Ridker PM: Novel inflammatory markers of coronary risk: theory versus practice. Circulation 1999;100:1148-1150.

122 Kutuk 0, Basaga H: Inflammation meets oxidation: NF-kappaB as a mediator of initial lesion development in atherosclerosis. Trends Mol Med 2003;9:549-557.

123 Mantovani A, Garlanda C, Locati M: Macrophage diversity and polarization in atherosclerosis: a question of balance. Arterioscler Thromb Vasc Biol 2009;29:1419-1423.

124 Barlic J, Zhang Y, Murphy PM: Atherogenic lipids induce adhesion of human coronary artery smooth muscle cells to macrophages by up-regulating chemokine CX3CL1 on smooth muscle cells in a TNFalphaNFkappaB-dependent manner. J Biol Chem 2007;282:19167-19176.

125 Packard RR, Libby P: Inflammation in atherosclerosis: from vascular biology to biomarker discovery and risk prediction. Clin Chem 2008;54:24-38.

126 Raffetto JD, Khalil RA: Matrix metalloproteinases and their inhibitors in vascular remodeling and vascular disease. Biochem Pharmacol 2008;75:346-359.

127 Libby P: Atherosclerosis: disease biology affecting the coronary vasculature. Am J Cardiol 2006;98:3Q-9Q.

128 Zhu H, Tannous P, Johnstone JL, Kong Y, Shelton JM, Richardson JA, Le V, Levine B, Rothermel BA, Hill JA: Cardiac autophagy is a maladaptive response to hemodynamic stress. J Clin Invest 2007;117:1782-1793.

129 Gutierrez MG, Master SS, Singh SB, Taylor GA, Colombo MI, Deretic V: Autophagy is a defense mechanism inhibiting BCG and Mycobacterium tuberculosis survival in infected macrophages. Cell 2004;119:753-766.

130 Xu K, Yang Y, Yan M, Zhan J, Fu X, Zheng X: Autophagy plays a protective role in free cholesterol overloadinduced death of smooth muscle cells. J Lipid Res 2010;51:2581-2590.

131 Jia G, Cheng G, Gangahar DM, Agrawal DK: Insulin-like growth factor-1 and TNF-alpha regulate autophagy through c-jun N-terminal kinase and Akt pathways in human atherosclerotic vascular smooth cells. Immunol Cell Biol 2006;84:448-454.

132 Martinon F, Mayor A, Tschopp J: The inflammasomes: guardians of the body. Annu Rev Immunol 2009;27:229-265.

133 Jia G, Cheng G, Agrawal DK: Autophagy of vascular smooth muscle cells in atherosclerotic lesions. Autophagy 2007;3:63-64.

134 Schrijvers DM, De Meyer GR, Herman AG, Martinet W: Phagocytosis in atherosclerosis: Molecular mechanisms and implications for plaque progression and stability. Cardiovasc Res 2007;73:470-480.

135 Zhang Y, Xu M, Xia M, Li X, Boini KM, Wang M, Gulbins E, Ratz PH, Li PL: Defective autophagosome trafficking contributes to impaired autophagic flux in coronary arterial myocytes lacking CD38 gene. Cardiovasc Res 2014;102:68-78. 


\section{Cellular Physiology Cell Physiol Biochem 2021;55:277-300

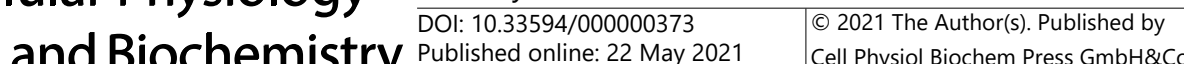 and Biochemistry Published online: 22 May 2021 Cell Physiol Biochem Press GmbH\&Co. KG \\ Bhat et al.: Lysosome and Cardiovascular Diseases}

136 Bao JX, Zhang QF, Wang M, Xia M, Boini KM, Gulbins E, Zhang Y, Li PL: Implication of CD38 gene in autophagic degradation of collagen I in mouse coronary arterial myocytes. Front Biosci (Landmark Ed) 2017;22:558-569.

137 Li X, Xu M, Pitzer AL, Xia M, Boini KM, Li PL, Zhang Y: Control of autophagy maturation by acid sphingomyelinase in mouse coronary arterial smooth muscle cells: protective role in atherosclerosis. J Mol Med (Berl) 2014;92:473-485.

138 Yuan X, Bhat OM, Lohner H, Li N, Zhang Y, Li PL: Inhibitory effects of growth differentiation factor 11 on autophagy deficiency-induced dedifferentiation of arterial smooth muscle cells. Am J Physiol Heart Circ Physiol 2019;316:H345-H356.

139 Ikeda S, Ushio-Fukai M, Zuo L, Tojo T, Dikalov S, Patrushev NA, Alexander RW: Novel role of ARF6 in vascular endothelial growth factor-induced signaling and angiogenesis. Circ Res 2005;96:467-475.

140 Legler DF, Micheau 0, Doucey MA, Tschopp J, Bron C: Recruitment of TNF receptor 1 to lipid rafts is essential for TNFalpha-mediated NF-kappaB activation. Immunity 2003;18:655-664.

141 Jin S, Yi F, Li PL: Contribution of lysosomal vesicles to the formation of lipid raft redox signaling platforms in endothelial cells. Antioxidants \& redox signaling 2007;9:1417-1426.

142 Zuo L, Ushio-Fukai M, Ikeda S, Hilenski L, Patrushev N, Alexander RW: Caveolin-1 is essential for activation of Rac1 and NAD(P)H oxidase after angiotensin II type 1 receptor stimulation in vascular smooth muscle cells: role in redox signaling and vascular hypertrophy. Arterioscler Thromb Vasc Biol 2005;25:1824-1830.

143 Yang B, Rizzo V: TNF-alpha potentiates protein-tyrosine nitration through activation of NADPH oxidase and eNOS localized in membrane rafts and caveolae of bovine aortic endothelial cells. Am J Physiol Heart Circ Physiol 2007;292:H954-962.

144 Cai H: NAD(P)H oxidase-dependent self-propagation of hydrogen peroxide and vascular disease. Circ Res 2005;96:818-822.

145 Suzuki YJ, Ford GD: Redox regulation of signal transduction in cardiac and smooth muscle. J Mol Cell Cardiol 1999;31:345-353.

146 Eum SY, Andras I, Hennig B, Toborek M: NADPH oxidase and lipid raft-associated redox signaling are required for PCB153-induced upregulation of cell adhesion molecules in human brain endothelial cells. Toxicol Appl Pharmacol 2009;240:299-305.

147 Peshavariya H, Dusting GJ, Di Bartolo B, Rye KA, Barter PJ, Jiang F: Reconstituted high-density lipoprotein suppresses leukocyte NADPH oxidase activation by disrupting lipid rafts. Free Radic Res 2009;43:772-782.

148 Jin S, Yi F, Zhang F, Poklis JL, Li PL: Lysosomal targeting and trafficking of acid sphingomyelinase to lipid raft platforms in coronary endothelial cells. Arterioscler Thromb Vasc Biol 2008;28:2056-2062.

149 Jin S, Zhang Y, Yi F, Li PL: Critical role of lipid raft redox signaling platforms in endostatin-induced coronary endothelial dysfunction. Arterioscler Thromb Vasc Biol 2008;28:485-490.

150 Huynh C, Roth D, Ward DM, Kaplan J, Andrews NW: Defective lysosomal exocytosis and plasma membrane repair in Chediak-Higashi/beige cells. Proc Natl Acad Sci U S A 2004;101:16795-16800.

151 Jaiswal JK, Andrews NW, Simon SM: Membrane proximal lysosomes are the major vesicles responsible for calcium-dependent exocytosis in nonsecretory cells. J Cell Biol 2002;159:625-635.

152 Xia M, Zhang C, Boini KM, Thacker AM, Li PL: Membrane raft-lysosome redox signalling platforms in coronary endothelial dysfunction induced by adipokine visfatin. Cardiovasc Res 2011;89:401-409.

153 Qiu H, Edmunds T, Baker-Malcolm J, Karey KP, Estes S, Schwarz C, Hughes H, Van Patten SM: Activation of human acid sphingomyelinase through modification or deletion of C-terminal cysteine. J Biol Chem 2003;278:32744-32752.

154 Zhang AY, Yi F, Jin S, Xia M, Chen QZ, Gulbins E, Li PL: Acid sphingomyelinase and its redox amplification in formation of lipid raft redox signaling platforms in endothelial cells. Antioxid Redox Signal 2007;9:817-828.

155 Bao JX, Xia M, Poklis JL, Han WQ, Brimson C, Li PL: Triggering role of acid sphingomyelinase in endothelial lysosome-membrane fusion and dysfunction in coronary arteries. Am J Physiol Heart Circ Physiol 2010;298:H992-H1002.

156 Koka S, Xia M, Chen Y, Bhat OM, Yuan X, Boini KM, Li PL: Endothelial NLRP3 inflammasome activation and arterial neointima formation associated with acid sphingomyelinase during hypercholesterolemia. Redox Biol 2017;13:336-344.

157 Yuan X, Wang L, Bhat OM, Lohner H, Li PL: Differential effects of short chain fatty acids on endothelial Nlrp3 inflammasome activation and neointima formation: Antioxidant action of butyrate. Redox Biol 2018;16:2131. 


\section{Cellular Physiology Cell Physiol Biochem 2021;55:277-300

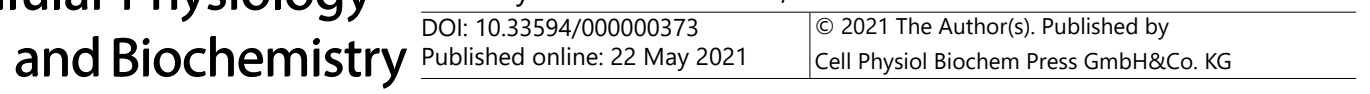 \\ Bhat et al.: Lysosome and Cardiovascular Diseases}

158 Mariathasan S, Newton K, Monack DM, Vucic D, French DM, Lee WP, Roose-Girma M, Erickson S, Dixit VM: Differential activation of the inflammasome by caspase-1 adaptors ASC and Ipaf. Nature 2004;430:213-218.

159 Zhou R, Tardivel A, Thorens B, Choi I, Tschopp J: Thioredoxin-interacting protein links oxidative stress to inflammasome activation. Nat Immunol 2010;11:136-140.

160 Dinarello CA, Donath MY, Mandrup-Poulsen T: Role of IL-1beta in type 2 diabetes. Curr Opin Endocrinol Diabetes Obes 2010;17:314-321.

161 Neven B, Callebaut I, Prieur AM, Feldmann J, Bodemer C, Lepore L, Derfalvi B, Benjaponpitak S, Vesely R, Sauvain MJ, Oertle S, Allen R, Morgan G, Borkhardt A, Hill C, Gardner-Medwin J, Fischer A, de Saint Basile G: Molecular basis of the spectral expression of CIAS1 mutations associated with phagocytic cell-mediated autoinflammatory disorders CINCA/NOMID, MWS, and FCU. Blood 2004;103:2809-2815.

162 Duewell P, Kono H, Rayner KJ, Sirois CM, Vladimer G, Bauernfeind FG, Abela GS, Franchi L, Nunez G, Schnurr M, Espevik T, Lien E, Fitzgerald KA, Rock KL, Moore KJ, Wright SD, Hornung V, Latz E: NLRP3 inflammasomes are required for atherogenesis and activated by cholesterol crystals. Nature 2010;464:1357-1361.

163 Abais JM, Xia M, Zhang Y, Boini KM, Li PL: Redox regulation of NLRP3 inflammasomes: ROS as trigger or effector? Antioxid Redox Signal 2015;22:1111-1129.

164 Martinon F, Petrilli V, Mayor A, Tardivel A, Tschopp J: Gout-associated uric acid crystals activate the NALP3 inflammasome. Nature 2006;440:237-241.

165 Heneka MT, Kummer MP, Stutz A, Delekate A, Schwartz S, Vieira-Saecker A, Griep A, Axt D, Remus A, Tzeng TC, Gelpi E, Halle A, Korte M, Latz E, Golenbock DT: NLRP3 is activated in Alzheimer's disease and contributes to pathology in APP/PS1 mice. Nature 2013;493:674-678.

166 Li X, Zhang Y, Xia M, Gulbins E, Boini KM, Li PL: Activation of Nlrp3 inflammasomes enhances macrophage lipid-deposition and migration: implication of a novel role of inflammasome in atherogenesis. PLoS One 2014;9:e87552.

167 Zhang C, Boini KM, Xia M, Abais JM, Li X, Liu Q, Li PL: Activation of Nod-like receptor protein 3 inflammasomes turns on podocyte injury and glomerular sclerosis in hyperhomocysteinemia. Hypertension 2012;60:154-162.

168 Xia M, Boini KM, Abais JM, Xu M, Zhang Y, Li PL: Endothelial NLRP3 inflammasome activation and enhanced neointima formation in mice by adipokine visfatin. Am J Pathol 2014;184:1617-1628.

169 Chen Y, Li X, Boini KM, Pitzer AL, Gulbins E, Zhang Y, Li PL: Endothelial Nlrp3 inflammasome activation associated with lysosomal destabilization during coronary arteritis. Biochim Biophys Acta 2015;1853:396408.

170 Zhang Y, Li X, Pitzer AL, Chen Y, Wang L, Li PL: Coronary endothelial dysfunction induced by nucleotide oligomerization domain-like receptor protein with pyrin domain containing 3 inflammasome activation during hypercholesterolemia: beyond inflammation. Antioxid Redox Signal 2015;22:1084-1096.

171 Yuan X, Bhat OM, Meng N, Lohner H, Li PL: Protective Role of Autophagy in Nlrp3 Inflammasome Activation and Medial Thickening of Mouse Coronary Arteries. Am J Pathol 2018;188:2948-2959.

172 Yuan X, Bhat OM, Lohner H, Zhang Y, Li PL: Endothelial acid ceramidase in exosome-mediated release of NLRP3 inflammasome products during hyperglycemia: Evidence from endothelium-specific deletion of Asah1 gene. Biochim Biophys Acta Mol Cell Biol Lipids 2019;1864:158532.

173 Anderson RG, Vasile E, Mello RJ, Brown MS, Goldstein JL: Immunocytochemical visualization of coated pits and vesicles in human fibroblasts: relation to low density lipoprotein receptor distribution. Cell 1978;15:919-933.

174 Daniels TF, Killinger KM, Michal JJ, Wright RW, Jr., Jiang Z: Lipoproteins, cholesterol homeostasis and cardiac health. Int J Biol Sci 2009;5:474-488.

175 Xu X, Yuan X, Li N, Dewey WL, Li PL, Zhang F: Lysosomal cholesterol accumulation in macrophages leading to coronary atherosclerosis in CD38(-/-) mice. J Cell Mol Med 2016;20:1001-1013.

176 Jerome WG, Yancey PG: The role of microscopy in understanding atherosclerotic lysosomal lipid metabolism. Microsc Microanal 2003;9:54-67.

177 Miller BF, Kothari HV: Increased activity of lysosomal enzymes in human atherosclerotic aortas. Exp Mol Pathol 1969;10:288-294.

178 Fowler S, Berberian PA, Shio H, Goldfischer S, Wolinsky H: Characterization of cell populations isolated from aortas of rhesus monkeys with experimental atherosclerosis. Circ Res 1980;46:520-530. 


\section{Cellular Physiology Cell Physiol Biochem 2021;55:277-300}

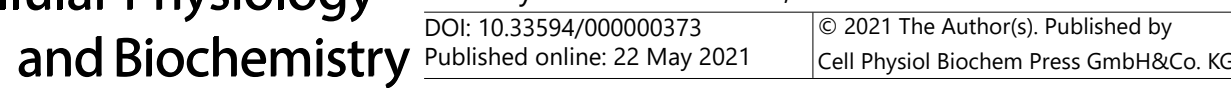

Bhat et al.: Lysosome and Cardiovascular Diseases

179 Bach G: Mucolipidosis type IV. Mol Genet Metab 2001;73:197-203.

180 Slaugenhaupt SA: The molecular basis of mucolipidosis type IV. Curr Mol Med 2002;2:445-450.

181 Loftus SK, Morris JA, Carstea ED, Gu JZ, Cummings C, Brown A, Ellison J, Ohno K, Rosenfeld MA, Tagle DA, Pentchev PG, Pavan WJ: Murine model of Niemann-Pick C disease: mutation in a cholesterol homeostasis gene. Science 1997;277:232-235. 